\title{
A systematic review of recent developments in disaster waste management
}

Fanshun Zhang, Cejun Cao, Congdong Li, Yang Liu and Donald Huisingh

The self-archived postprint version of this journal article is available at Linköping University Institutional Repository (DiVA):

http://urn.kb.se/resolve?urn=urn:nbn:se:liu:diva-160380

N.B.: When citing this work, cite the original publication.

Zhang, F., Cao, C., Li, C., Liu, Y., Huisingh, D., (2019), A systematic review of recent developments in disaster waste management, Journal of Cleaner Production, 235, 822-840.

https://doi.org/10.1016/j.jclepro.2019.06.229

Original publication available at:

https://doi.org/10.1016/j.jclepro.2019.06.229

Copyright: Elsevier

http://www.elsevier.com/

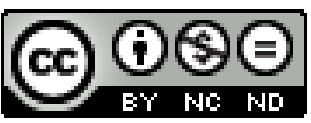




\section{Accepted Manuscript}

A systematic review of recent developments in disaster waste management

Fanshun Zhang, Cejun Cao, Congdong Li, Yang Liu, Donald Huisingh

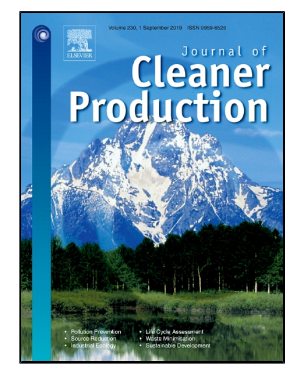

PII:

S0959-6526(19)32194-8

DOI:

10.1016/j.jclepro.2019.06.229

Reference:

JCLP 17398

To appear in:

Journal of Cleaner Production

Received Date:

31 December 2018

Accepted Date:

21 June 2019

Please cite this article as: Fanshun Zhang, Cejun Cao, Congdong Li, Yang Liu, Donald Huisingh, A systematic review of recent developments in disaster waste management, Journal of Cleaner Production (2019), doi: 10.1016/j.jclepro.2019.06.229

This is a PDF file of an unedited manuscript that has been accepted for publication. As a service to our customers we are providing this early version of the manuscript. The manuscript will undergo copyediting, typesetting, and review of the resulting proof before it is published in its final form. Please note that during the production process errors may be discovered which could affect the content, and all legal disclaimers that apply to the journal pertain. 


\title{
Word count: 13848
}

\section{A systematic review of recent developments in disaster waste management}

Fanshun Zhang a , Cejun Cao ${ }^{\text {b, c }}$, Congdong Li ${ }^{\text {a, }}$, Yang Liu d, e, f, **, Donald Huisingh ${ }^{\mathrm{g}}$

a School of Management, Jinan University, Guangzhou, 510632, China

b School of Business Planning, Chongqing Technology and Business University, Chongqing, 400067, China

${ }^{\mathrm{c}}$ College of Management and Economics, Tianjin University, Tianjin, 300072, China

d Institute of Physical Internet, Jinan University (Zhuhai Campus), Zhuhai, 519070, China

e Department of Management and Engineering, Linköping University, SE-581 83 Linköping, Sweden

${ }^{\mathrm{f}}$ Department of Production, University of Vaasa, 65200 Vaasa, Finland

g The Institute for a Secure and Sustainable Environment, University of Tennessee, Knoxville, USA

*Corresponding authors: licd@jnu.edu.cn (C.D. Li), yang.liu@liu.se (Y. Liu)

\begin{abstract}
Disaster waste management received increasing attention in recent year, but there was no review updating the evolving development after the study of Brown et al. (2011a). To explore how the topics in disaster waste management evolved in recent years and to analyze whether the gaps identified by Brown et al. (2011a) are covered, 82 papers published from 2011 to 2019 were selected from the Scopus database based on the defined process and criteria, to systematically examine the disaster waste management research from nine aspects of planning, waste, waste treatment options, environment, economics, social considerations, organizational aspects, legal frameworks and funding. The results suggested that there were no obvious changes or developments in the field of disaster waste management, although a few research gaps have been addressed, such as waste separation, waste quantities, case studies of incineration and waste to energy, direct economic effects, social considerations as well as application of GIS technology. Except for the comparative studies, future directions were suggested by the gaps that persist since Brown et al. (2011a) and the new gaps that were identified in this review.
\end{abstract}

Keywords: Waste management; disaster context; systematic review 


\section{Contents}

1. Introduction

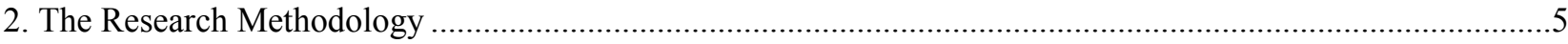

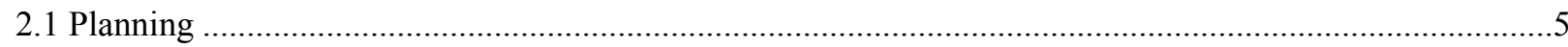

2.2 Searching

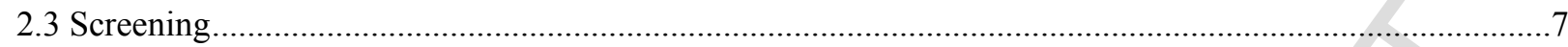

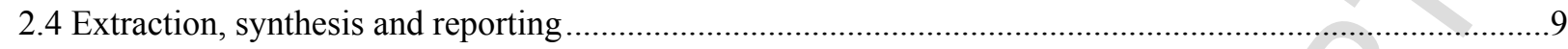

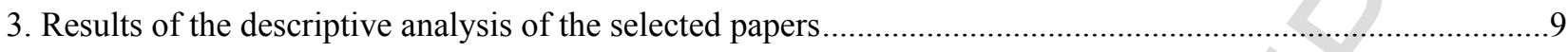

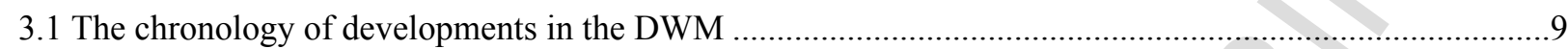

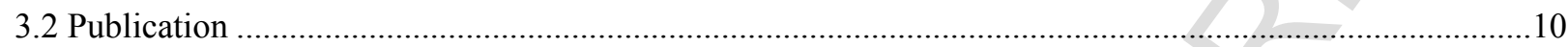

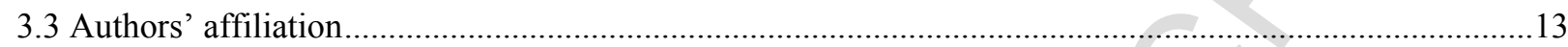

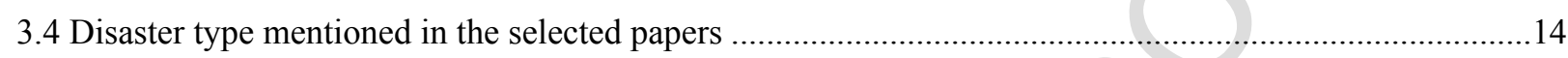

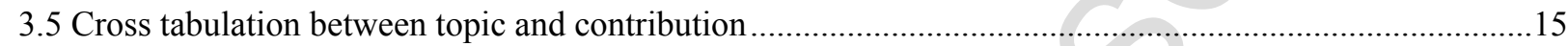

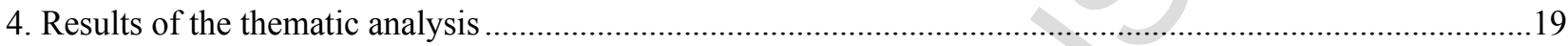

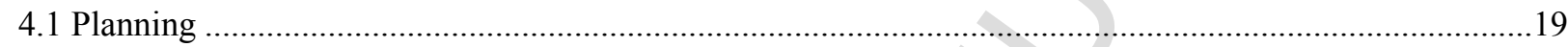

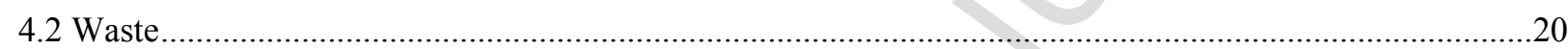

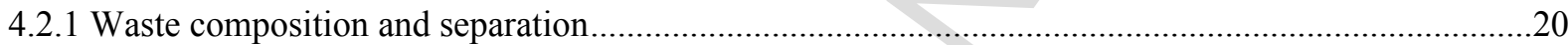

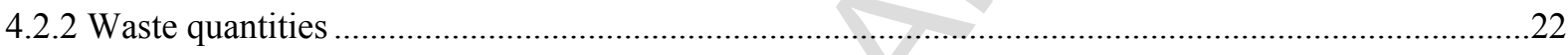

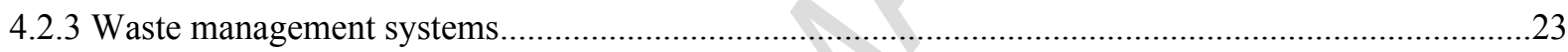

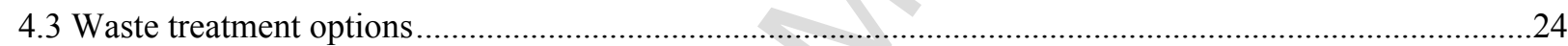

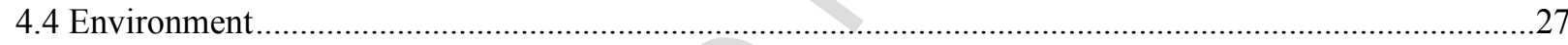

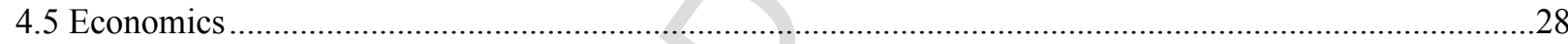

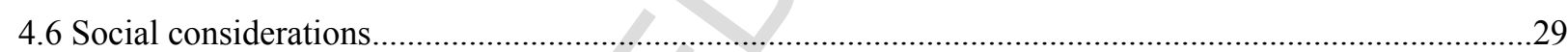

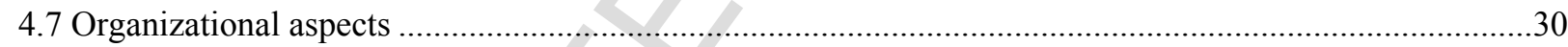

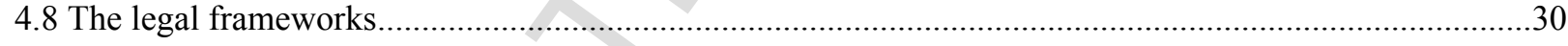

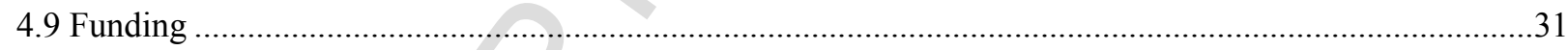

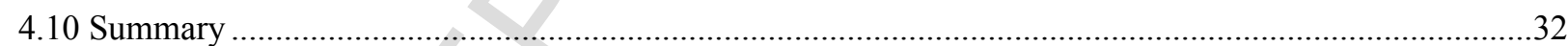

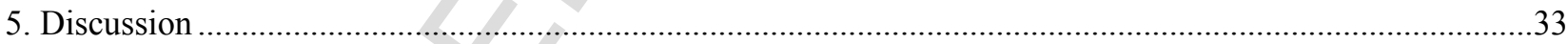

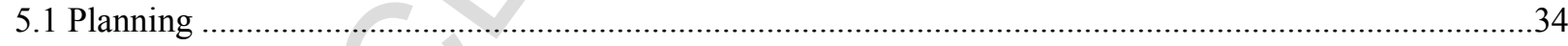

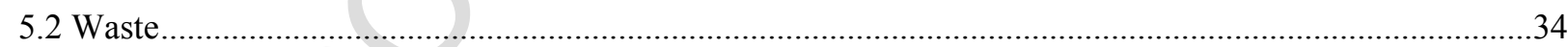

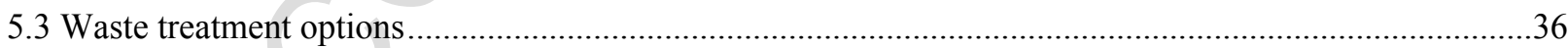

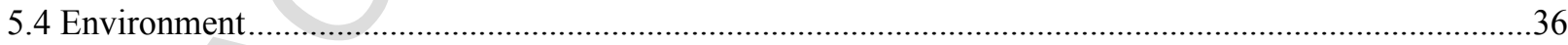

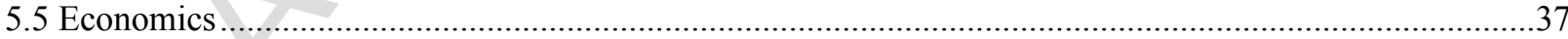

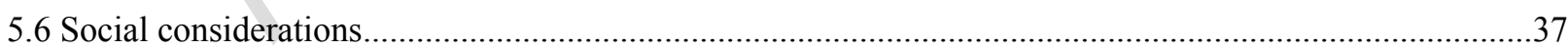

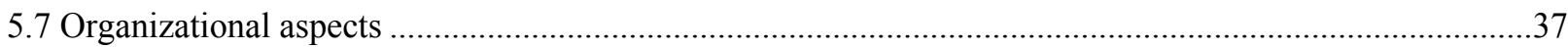

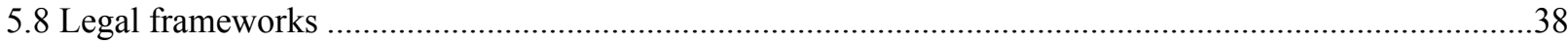

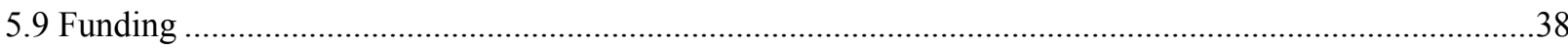

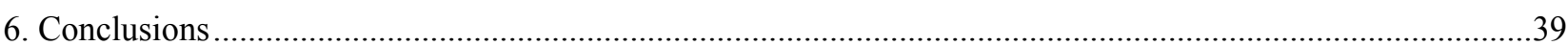




\section{Introduction}

Based on the International Disaster Databases (EM-DAT), the total number of natural or man-made disasters has dramatically increased in recent years. As clarified by Brown et al. (2011a), disasters not only caused economic, environmental and social losses, but produced a large amount of waste. For instance, more than 100 million tons of solid waste were produced in hurricane Katrina (Lorca et al., 2017). The Wenchuan earthquake, the Great East Japan earthquake and Canterbury earthquake respectively generated solid waste of more than 380, 27.99 and 8 million tons (Xiao et al., 2012; Domingo and Luo, 2017; Sasao, 2016). Such gigantic amounts of wastes challenge the effectiveness of response and recovery actions (Brown et al., 2011a), which are summarized as the following aspects:

(1) Compared with the municipal waste in "peace time", waste volumes generated in disaster contexts are 5-15 times, and those quantities are difficult to be properly managed by traditional managerial strategies/approaches.

(2) For emergency organizations, road blockage caused by disaster waste poses challenge to access affected area within a short time. Moreover, it may cause other unexpected losses (e.g. affected populations and economic losses);

(3) Waste exposed in affected areas may induce infections, and further threaten public safety and health. In addition to that, poor clearance of disaster waste aggravates the psychological burden (e.g. emotional stress) of victims. In this sense, it has a negative impact on the effectiveness of psychological recovery. Consequently, it is critical to investigate these issues with respect to disaster waste management (DWM).

With respect to DWM, related studies are strongly scattered across different disciplines, methods (e.g. qualitative and quantitative) and fields (e.g. environment science, disaster operations management and management science). Therefore, a clear picture of DWM research is vacant because little prior research focuses on aggregating these literatures systematically. Although, a few earlier literature reviews covered a large number of studies (e.g. Ekici et al., 2009, Brown et al., 2011a), there was no research using the clearly defined processes and criteria to systematically review the relevant literature. As Cook et al. (1997) portrayed it, systematic review synthesized in a transparent and reproducible way are helpful in improving the decision-making and practice of 
academics and practitioners by the identification of contradictory evidence. This method is a key tool to develop the evidence base, and it is also widely applied in the field of management (Nurmala et al., 2017; Anaya-Arenas et al., 2014).

On the other hand, the need and challenge of DWM research were highlighted by four editorials (Milke, 2011; Periathamby et al., 2012; Taebi and van de Poel, 2015; Denot, 2016). Moreover, DWM was identified as a critical research gap in the field of disaster operations management (Altay and Green, 2006; Galindo and Batta, 2013; Gupta et al., 2016), and was suggested for more attention. Inspired by such recommendations and suggestions, an increasing number of researchers discussed the topic of DWM from several aspects in recent year.

However, since Brown et al. (2011a) presented a comprehensive review before 2010, there is no updated work to summarize the recent studies. Consequently, the purpose of this paper was to develop an updated systematic literature review using the categories adopted by Brown et al. (2011a) and to present a new "blueprint" of DWM research based on the comparative analysis with the study of Brown et al. (2011a).

To achieve this goal, an interdisciplinary and systematic review of 82 key papers in a time frame since Brown et al. (2011a) to date (between 2011 and 2019) was conducted, and the inclusion and exclusion criteria of key papers were discussed in subsection 2.3. The methods used were:

Firstly, according to Altay and Green (2006), Gaindo and Batta (2013) and Gupta et al. (2016), descriptive analysis was used from the selected classification scheme, in terms of chronology of development, publication, authors' affiliation, type of disaster and cross tabulation between topic and contribution.

Secondly, to make a clear contrast with Brown et al. (2011a), the structure of the thematic analysis used was based upon their study. In detail, the content of this DWM research systematically reviewed planning, waste, waste treatment options, environment, economics, social considerations, organizational aspects, legal framework and funding.

Thirdly, compared with research gaps identified by Brown et al. (2011a), the changes and developments of DWM research were summarized in this review.

Fourthly, recommendations for future directions were detailed.

Three contributions were made by the authors of this paper. Firstly, an updated literature review was analyzed here, which tracked recent developments of DWM research. Secondly, an 
interdisciplinary and systematic review was conducted to present a clear picture of DWM research, which provided basic guidance for both disaster managers and academics. Thirdly, the potential research directions were provided based on the gaps that persist since Brown et al. (2011a) and pertaining to the new gaps which were identified in this review. This provides the foundation for future research.

The remainder of this paper was structured as follows: Section 2 introduced the research methodology. Then, based on Tranfield et al. (2003), descriptive analysis and thematic analysis were presented in Section 3 and Section 4. Particularly, based upon the structure of Brown et al. (2011a), the recent literatures were analyzed from planning, waste, waste treatment options, environment, economic, social considerations, organizational aspects, legal frameworks and funding. Based on the results of comparative studies, the research gaps and future directions were detailed in Section 5. Finally, conclusions and limitations of this paper were included in Section 6

\section{The Research Methodology}

A systematic literature review was employed to analyze the papers covering the DWM research published from 2011 to 2019. Specially, the study of Brown et al. (2011a) provided the benchmark to structure this paper's content. Other sources (not related to DWM) were taken into account, to guide and improve the form and structure of this paper (Abidi et al., 2014; Reim et al., 2015; Annarelli et al., 2016; Calabrese et al., 2018; Altay and Green, 2006; Gupta et al., 2016; Galindo and Batta, 2013).

By definition, a systematic review should present a clear picture of a specific research question in a transparent and reproducible manner (Cook et al., 1997). To improve the validity and reliability, a list of specific steps should be carefully carried out (Leseure et al., 2004). Following the methodology proposed by Tranfield et al. (2003), four main steps (planning, searching, screening and extraction/synthesis/reporting) were used and detailed in the following subsections.

\subsection{Planning}

At the beginning of this review, a review panel (researchers majoring in waste management, disaster management, environment science) was constructed to discuss the research question and the needs of this review. After a detailed discussion, the following research questions (RQs) were defined. 
$R Q 1$. What is the current status of the research on DWM?

RQ2. Were the gaps identified by Brown et al. (2011a) covered or not?

RQ3. What challenges should be overcome in the future?

\subsection{Searching}

The inspiration of this paper came from a well-cited work of Brown et al. (2011a) who offered a review of DWM article, published between 1990-2010. To update the status of DWM, the time between 2011 to 2019 (until March 2019) was used for the literature search. The database of Scopus was used as search engine. Scopus is the largest multidisciplinary abstract and citation database of peer-reviewed literature (Geraldi et al., 2011), and both major and minor publishers (e.g. Elsevier, Emerald, Springer and Wiley) are covered in this database. Moreover, Scopus is regarded as one of the most complete databases when it comes to global research, and it is widely used by authors conducting a multidisciplinary systematic literature review (Reim et al., 2015; Calabrese et al., 2018).

Then, a structured keyword's search was conducted to identify the literature and to avoid the unbiased research. In this paper, waste management was the central topic, disaster was the context. Thus, the keywords should be detailed from two aspects, a. waste management, $b$. the context.

On the one hand, keywords with a focus upon waste management are chosen from Brown et al. (2011a). They emphasized that the term "debris" and "waste" were widely used by researchers interested in DWM research. In general, the term "debris" describes the largely inert building and vegetative materials, but the latter refers to the entire waste matrix (e.g. vegetative waste, construction and demolition (C\&D) waste, toxic chemical and post-disaster municipal waste). Besides, the meaning of word which is similar to "waste" and "debris" were also taken into consideration, such as "wastage", "rubbish", "garbage", "flotsam", "litter", "trash".

On the other hand, inspired by the study of Altay and Green (2006) and Gupta et al. (2016), the disaster context was described by the term "disaster", "natural hazards", "emergency crisis" and "catastrophe". Additionally, according to Gupta et al. (2016), DWM was closely associated with humanitarian logistics. Therefore, the term "humanitarian" was also used as a search word.

Based on the search process used, 1764 papers were identified as potentially relevant. Table. 1 displays the results of searching based on the selected keywords. 
Table. 1 The results of searching with different keywords for relevant papers for this literature review

\begin{tabular}{lllllll}
\hline Keywords & Disaster & Catastrophe & Natural hazards & Emergency crisis & Humanitarian & Total \\
\hline Waste & 565 & 34 & 309 & 39 & 40 & 987 \\
Debris & 403 & 19 & 149 & 4 & 9 & 584 \\
Wastage & 22 & 3 & 6 & 1 & 1 & 33 \\
Rubbish & 2 & 2 & 5 & 1 & 0 & 10 \\
Flotsam & 4 & 0 & 2 & 0 & 0 & 6 \\
Litter & 37 & 4 & 36 & 0 & 1 & 78 \\
Trash & 11 & 2 & 6 & 4 & 2 & 25 \\
Garbage & 16 & 1 & 18 & 2 & 4 & 41 \\
Total & & & & & & 1764 \\
\hline
\end{tabular}

\subsection{Screening}

To guarantee the fidelity and completeness of this review, the related papers were carefully reviewed by four researchers according to the inclusion and exclusion criteria (Table. 2), although, some subjectivity was inevitably involved in manual scrutiny of the papers, engaging four researchers helped to improve the objectivity of the screening process (Galindo and Batta, 2013).

As Table. 2 Presented, inclusion and exclusion criteria used for selecting papers under five categories: document type, language, availability of full text, subject and disaster contexts. According to the criteria, the process of screening was:

During the first screening, given that DWM is still an emerging topic (Gupta et al., 2016; Galindo and Batta, 2013) and a few meaningful research gaps mentioned by Brown et al. (2011a) were only discussed in conference papers, the journal and conference papers published in English were selected. Although the use of conference papers is uncommon in systematic literature reviews, due to the quality of papers (Reim et al., 2015), there were some conference papers considered into a systematic review. (Boehm and Thomas, 2013; Calabrese et al., 2018).

To further identify and select the most suitable papers, another two criteria about subject and disaster were analyzed. In terms of subject, the selected research concentrated on investigating the waste/debris management in disaster contexts. Usually, the effects of disaster on waste/debris management was emphasized in their studies. In contrast, some researches who addressed a specific technology, unsuitable waste management results in disasters and peace-time waste management were excluded. Regarding disaster contexts, it was difficult to judge whether an event was a disaster (Galindo and Batta, 2013). For example, can an airplane crash or a fire in a factory be considered as a disaster? To solve this challenge, the principle proposed by Galindo and Batta (2013) was adopted 
and detailed in Table. 2.

Table. 2 The following inclusion and exclusion criteria were used for selecting relevant papers for in-depth analysis

\begin{tabular}{|c|c|c|}
\hline Aspect & Inclusion criteria & Exclusion criteria \\
\hline Document type & Journal paper and conference paper. & Book chapter, editorial and comment. \\
\hline Language & All papers in English. & $\begin{array}{l}\text { Other languages, such as Chinese and } \\
\text { Japanese. }\end{array}$ \\
\hline $\begin{array}{l}\text { Availability of } \\
\text { full text }\end{array}$ & Available & Not available \\
\hline \multirow[t]{4}{*}{ Subject } & $\begin{array}{l}\text { 1. The Central topic was waste } \\
\text { management }\end{array}$ & $\begin{array}{l}\text { 1. Central topic is a specific technology, } \\
\text { such as microbial biotechnology, } \\
\text { architecture design, geotechnical } \\
\text { engineering and material technology } \\
\text { (especially construction materials). }\end{array}$ \\
\hline & $\begin{array}{l}\text { 2. Focus on the effects of a disaster on } \\
\text { waste management. }\end{array}$ & $\begin{array}{l}\text { 2. Focus on a disaster resulted from } \\
\text { unsuitable waste management. }\end{array}$ \\
\hline & $\begin{array}{l}\text { 3. Select key words with a focus upon } \\
\text { debris management. }\end{array}$ & 3. Keywords is management of debris-flow. \\
\hline & $\begin{array}{l}\text { 4. Concentrate on waste generated } \\
\text { from disasters, especially municipal } \\
\text { waste in disaster contexts was } \\
\text { included. }\end{array}$ & 4. Peace-time waste management. \\
\hline Disaster contexts & $\begin{array}{l}\text { The focus of the papers on disruptive } \\
\text { community disruptions which can } \\
\text { seldom be solved by using local } \\
\text { resources. Therefore, external } \\
\text { resources are needed such as in giant } \\
\text { earthquakes. (Galindo and Batta, 2013) }\end{array}$ & $\begin{array}{l}\text { The event did not seriously disrupt the } \\
\text { community, and was easy to be solved by } \\
\text { local resources, did not require participation } \\
\text { of non-local agencies, such as airplane crash } \\
\text { and resultant contaminated drinking water. } \\
\text { (Galindo and Batta, 2013) }\end{array}$ \\
\hline
\end{tabular}

After the review process was completed, 74 papers were selected for further analysis. According to Reim et al. (2015), the literature selected by keywords can be used as a secondary source of literature analysis. This led the authors select eight additional papers that contributed to DWM research. Therefore, 82 papers were selected for this systematic literature review, based on the searching and screening process. Fig. 1 outlined the process of locating, studying and evaluating papers. 


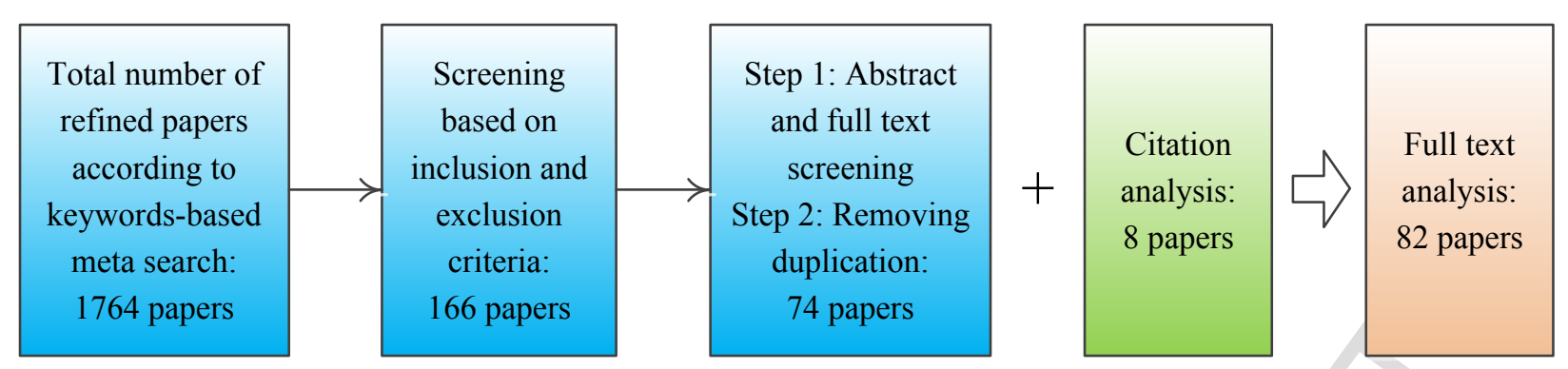

Fig. 1 Process of locating, studying and evaluating the papers

\subsection{Extraction, synthesis and reporting}

A good systematic review relies on a clear reporting of the selected papers. In general, a two-stage report including descriptive analysis and thematic analysis is necessary (Tranfield et al., 2003). Some authors refer to descriptive analysis as meta-analysis and statistical analysis, which provides a brief overview of a specific topic. Inspired by the well-cited studies of Altay and Green (2006) and Galindo and Batta (2013), papers subject to 'descriptive analysis' were analyzed from five aspects: a. chronology of developments, b. publication (e.g. journal paper and conference paper), c. authors' affiliation (e.g. developed country and developing country), d. type of disaster (e.g. general, earthquake, tsunami, hurricane, landslide, flood, bushfire, thunderstorm and man-made disaster), e. cross tabulation among contributions (e.g. theory, model and application) and topics (e.g. outline of DWM, plans/strategies of DWM, location of DWM site, identification of disaster waste as well as quantities of disaster waste).

Because the authors of this review article focused on updating the work of Brown et al. (2011a). Therefore, the thematic analyses were analyzed from: "planning", "waste", "waste management options", “environment", "economics", "social consideration", "organizational aspects", "legal frameworks" and "funding".

\section{Results of the descriptive analysis of the selected papers}

In this section, 82 papers were classified from five aspects: a. the chronology of developments, b. the mainstream journals in which they were published, c. the major authors' affiliations, d. the most mentioned disaster types, e. the important topics as well as their contributions in the field of DWM.

\subsection{The chronology of developments in the DWM}

To document the trends in the number of papers published on DWM, the analysis method used 
by Gupta et al. (2016) of the number of papers published each year, and by the method used by Sanders and Manfredo (2006), which was based upon two-year moving averages.

Table 3 presented the moving average beginning in 2012. The number of papers showed a continuously upward trend from 2013 and reached the highest point at 18 in 2016. The two-year moving average in 2017 was 16.5 (the highest compared with the previous year), which was due to the papers published in 2016 (eighteen) and 2017 (fifteen). Although the slightly downward trend was showed from 2017, the number of papers published still indicates that there is a growing attention to the DWM research (Compared with papers published before 2015).

Table 3. The number of selected papers reviewed by year

\begin{tabular}{ccc}
\hline Year & Number & Two-year moving average \\
\hline 2011 & 5 & - \\
2012 & 7 & 6 \\
2013 & 3 & 5 \\
2014 & 4 & 3.5 \\
2015 & 10 & 7 \\
2016 & 18 & 14 \\
2017 & 15 & 16.5 \\
2018 & 12 & 13.5 \\
2019 & 8 & 10 \\
Total & 82 & - \\
\hline
\end{tabular}

\subsection{Publication}

Motivated by Annarelli et al. (2016), the targeted papers were reviewed by publication, to identify the mainstream journals and their research fields. Table 4 reported the list of journals and conferences. In regard to journals, the top three journals with the number of papers included: Waste Management (eleven), the International Journal of Disaster Risk Reduction (nine), Resources, Conservation and Recycling (four). Additionally, Natural Hazards, Socio-Economic Planning Sciences, the Journal of Material Cycles and Waste Management, the Journal of Cleaner Production and Sustainability, each published, three of the selected papers.

Based upon these results, those observations were made: (1) Clearly main-stream of waste management researchers invested a special attention to DWM. Many papers were published in Waste Management, which was influenced by the editorials published in that journal in 2011 and 2016 (Milke, 2011; Denot, 2016). (2) Although nine papers published in the International Journal of Disaster Risk Reduction, DWM research received limited attention from the academics concentrating 
on disaster management, which may have resulted from the special attention to disaster response issues and strategies (Gupta et al., 2016). Regarding the subject areas covered by each journal, these observations were made: (1) It was clear that DWM research was closely linked to the environmentally-related areas, such as environmental sciences and environmental studies. (2) Given that earthquakes generated a large quantity of C\&D wastes, the related issues were widely discussed in the area of Engineering. (3) Remarkably, in the field of Operations Research and Management Science, DWM was treated as a reverse logistics system to investigate the traditional problem of logistic management (e.g. location of temporary storage site, allocation of resources and inventory management of processing site). 
Table 4. The number of papers selected for in-depth analysis for this review article according to journals and conferences

\begin{tabular}{|c|c|c|}
\hline Journal and conference & Subject area & Number \\
\hline Waste Management & Engineering, Environmental; Environmental Sciences & 11 \\
\hline International Journal of Disaster Risk & Geosciences, Multidisciplinary; Meteorology \& Atmospheric Sciences; Water Resources & 9 \\
\hline \multicolumn{3}{|l|}{ Reduction } \\
\hline Resources Conservation and Recycling & Engineering, Environmental; Environmental Sciences & 4 \\
\hline Natural Hazards & Geosciences, Multidisciplinary; Meteorology \& Atmospheric Sciences; Water Resources & 3 \\
\hline Socio-Economic Planning Sciences & Economics; Management; Operations Research \& Management Science & 3 \\
\hline Journal of Material Cycles and Waste & Environmental Sciences & 3 \\
\hline \multicolumn{3}{|l|}{ Management } \\
\hline \multirow[t]{2}{*}{ Journal of Cleaner Production } & Engineering, Environmental; Environmental Sciences; Green \& Sustainable Science \& & 3 \\
\hline & Technology & \\
\hline Sustainability & Environmental Sciences; Environmental Studies; Green \& Sustainable Science \& Technology & 3 \\
\hline Disaster Prevention and Management & Environmental Studies; Management; Public, Environmental \& Occupational Health & 2 \\
\hline Waste Management and Research & Engineering, Environmental; Environmental Sciences & 2 \\
\hline Landscape and Urban Planning & Ecology; Environmental Studies; Geography; Geography, Physical; Urban Studies & 1 \\
\hline Biosecurity and Bioterrorism - Biodefense & International Relations; Public, Environmental \& Occupational Health & 1 \\
\hline Strategy Practice and Science & & \\
\hline Australian Journal of Emergency & - & 1 \\
\hline Management & & \\
\hline Operations Management Research & Management & 1 \\
\hline Journal of Civil Engineering and & Engineering, Civil & 1 \\
\hline Management & & \\
\hline International Journal of Applied Earth & Remote Sensing & 1 \\
\hline Observation and Geoinformation & & \\
\hline Environmental Science and Technology & Engineering, Environmental; Environmental Sciences & 1 \\
\hline Natural Hazards and Earth System Sciences & Geosciences, Multidisciplinary; Meteorology \& Atmospheric Sciences; Water Resources & 1 \\
\hline International Journal of Emergency & - & 1 \\
\hline Management & & \\
\hline Transportation Research Part B - & Economics; Engineering, Civil; Operations Research \& Management Science; Transportation; & 1 \\
\hline Methodological & Transportation Science \& Technology & \\
\hline Disasters & Planning \& Development & 1 \\
\hline International Journal of Urban Sciences & & 1 \\
\hline Operations Research & Management; Operations Research \& Management Science & 1 \\
\hline Expert Systems with Application & Computer Science, Artificial Intelligence; Engineering, Electrical \& Electronic; Operations & 1 \\
\hline Engineering Construction and Architectural & (a) & 1 \\
\hline Management & & \\
\hline Jurnal Teknologi & Engineering, Civil; Engineering, Industrial; Management & 1 \\
\hline Science of the Total Environment & Environmental Sciences & 1 \\
\hline Memoirs of the Faculty of Engineering & - & 1 \\
\hline EURO Journal on Computational & - & 1 \\
\hline Optimization & & \\
\hline International Journal of Environmental & Environmental Sciences & 1 \\
\hline Science and Technology & & \\
\hline
\end{tabular}




\section{Journal and conference}

ISPRS Journal of Photogrammetry and

Remote Sensing

Clean Technologies and Environmental Policy

Plos One

Journal of Environmental Science and

Technology

Renewable and Sustainable Energy

Reviews

Geomatics Natural Hazards and Risk

Production and Operations Management Global Journal of Environmental Science and Management

Journal of Environmental Management Spatial Information Research

Risk Analysis

Computer-Aided Civil and Infrastructure

Engineering

Transportmetrica A - Transport Science International Journal of Urban and

Regional Research

\section{Subject area}

Number

Geography, Physical; Geosciences, Multidisciplinary; Imaging Science \& Photographic

Technology; Remote Sensing

Engineering, Environmental; Environmental Sciences; Green \& Sustainable Science \& Technology

Multidisciplinary Sciences

Energy \& Fuels; Green \& Sustainable Science \& Technology

Geosciences, Multidisciplinary; Meteorology \& Atmospheric Sciences; Water Resources 1

Engineering, Manufacturing; Operations Research \& Management Science /

Environmental Sciences

$-$

Mathematics, Interdisciplinary Applications; Public, Environmental \& Occupational Health;

Social Sciences, Mathematical Methods

Computer Science, Interdisciplinary Applications; Construction \& Building Technology;

Engineering, Civil; Transportation Science \& Technology

Transportation; Transportation Science \& Technology $\quad 1$

Geography; Planning \& Development; Urban Studies 


\subsection{Authors' affiliation}

Brown et al. (2011a) argued that DWM research was seldom performed by scholars from developing countries. To analyze whether that tendency persisted or not, the number of papers reviewed by country of the academic's affiliation was shown in Table 5.

Table 5. The number of papers according to the developed and developing country affiliations of the authors.

\begin{tabular}{|c|c|c|c|c|c|}
\hline Affiliation & Country & Number & Affiliation & Country & Number \\
\hline Kyoto University & Japan & 4 & Rochester Institute of Technology & USA & 1 \\
\hline Kobe University & Japan & 4 & Dogus University & Turkey & 1 \\
\hline The University of Melbourne & Australia & 4 & $\begin{array}{l}\text { UNEP International Environmental } \\
\text { Technology Centre }\end{array}$ & Japan & 1 \\
\hline University of Moratuwa & Sri Lanka & 3 & Pacific Northwest National Laboratory & USA & 1 \\
\hline Universiti Teknologi Mara & Malaysia & 3 & Universidade Federal do Rio de Janeiro & Brazil & 1 \\
\hline Middle East Technical University & Turkey & 2 & Muroran Institute of Technology & Japan & 1 \\
\hline Islamic Azad University & Iran & 2 & Pontificia Universidad Católica del Perú & Perú & 1 \\
\hline University of Canterbury & New Zealand & 2 & Chulalongkorn University & Thailand & 1 \\
\hline Radford University & USA & 2 & $\begin{array}{l}\text { University of Engineering and Technology } \\
\text { Lahore }\end{array}$ & Pakistan & 1 \\
\hline Hanyang University & South Korea & 2 & Toyo University & Japan & 1 \\
\hline Western Carolina University & USA & 2 & National University of Singapore & Singapore & 1 \\
\hline Shanghai Maritime University & China & 2 & Università Politecnica of Marche & Italy & 1 \\
\hline University of Florida & USA & 2 & International Solid Waste Association Austria & USA & 1 \\
\hline Kyushu University & Japan & 2 & Seoul National University & South Korea & 1 \\
\hline University of Bologna & Italy & 2 & Iwate University & Japan & 1 \\
\hline Okumura Corporation & Japan & & Hokkaido University of Education & Japan & 1 \\
\hline $\begin{array}{l}\text { Pontificia Universidad Católica } \\
\text { de Chile }\end{array}$ & Chile & 1 & Academy of Military Medical Sciences & China & 1 \\
\hline Indian Inst Management Rohtak & India & 1 & Programme of Biomedical Science & Malaysia & 1 \\
\hline Universite du Quebec a Montreal & Canada & 1 & Taean Environmental Health Center & South Korea & 1 \\
\hline University of Waikato & New Zealand & 1 & Tokyo Metropolitan University & Japan & 1 \\
\hline University of Padova & Italy & 1 & Northern Illinois University & USA & 1 \\
\hline University of Hawaii at Manoa & USA & 1 & Tongii University & China & 1 \\
\hline Purdue University & USA & 1 & University of Brescia & Italy & 1 \\
\hline Shanghai Jiao Tong University & China & 1 & Harvard University & USA & 1 \\
\hline $\begin{array}{l}\text { National Geospatial-Intelligence } \\
\text { Agency }\end{array}$ & USA & 1 & Shenzhen University & China & 1 \\
\hline Bilkent University & Turkey & 1 & University of Paris Est-Marne la Vallee & France & 1 \\
\hline Yeditepe University & Turkey & 1 & Korea Environment Institute & South Korea & 1 \\
\hline Resilient Organisations & New Zealand & 1 & Kyungpook National University & South Korea & 1 \\
\hline Tohoku University & Japan & 1 & Louisiana State University & USA & 1 \\
\hline \multirow[t]{2}{*}{ Massey University } & New Zealand & 1 & & & \\
\hline & & & & \multicolumn{2}{|c|}{ Total: 82} \\
\hline
\end{tabular}


It was found that twenty-six papers $(31.7 \%)$ were published by academics from developing countries, and $68.3 \%$ of the papers were published by scholars from developed countries, with the criteria of developing/developed countries according to the Human Development Reports (United Nations, 2018). These results showed a shift from those reported by Brown et al. (2011a), although the authors from developed countries still published a higher percentage of the papers than the authors from developing countries.

\subsection{Disaster type mentioned in the selected papers}

Disaster waste closely depend upon the type of disaster (Brown et al, 2011a). After careful scanning, the authors of this review found that a few authors discussed waste management in various disaster contexts (Tabata et al., 2017; Wakabayashi et al., 2017; Asari et al., 2013; Koyama et al., 2016; Pramudita and Taniguchi, 2014). Therefore, the total number of papers reviewed by disaster type was 89. From Table 6, some observations were made: (1) About 37\% papers (Thirty-three) analyzed DWM in the context of earthquakes, which may result from easy identification and quantification of C\&D wastes. (2) Apart from earthquakes, other disaster types were not deeply discussed, especially in the context of man-made disasters. (3) General studies indicate that many of the paper's author (twenty-two) paid no attention to different disaster contexts. However, the DWM research is still in its early stage. Too many generalizations are less likely to guide the practical and future research in any particular situations. A similar viewpoint was also suggested to focus on the specific disaster contexts (Brown et al., 2011a; Gupta et al., 2016). 
Table 6. The number of papers reviewed by disaster type

\begin{tabular}{|c|c|c|}
\hline Type & Literature & Number \\
\hline General & $\begin{array}{l}\text { Brown and Milke (2016), Takeda et al. (2015), Trivedi et al. (2015), Brown et al. (2011a), } \\
\text { Grzeda. et al (2014), Yusof et al. (2016), Crowley and Flachsbart (2018), Kim and Hong } \\
\text { (2017), Crowley (2017), Francesco et al. (2018), Regattieri et al. (2018), Boonmee et al. } \\
\text { (2018), Otsuka and Katsumi (2015), Wang et al. (2019), Ozdamar et al. (2014), Lesperance et } \\
\text { al. (2011), Zawawi et al. (2018), Yoo et al. (2017), Zawawi et al. (2015), Maryono et al. } \\
\text { (2015), Caniato et al. (2016), Regattieri et al. (2016) and Baek et al. (2016); }\end{array}$ & 23 \\
\hline Earthquake & $\begin{array}{l}\text { Sasao (2016), Asari. et al (2013), Tabata. et al (2017; 2016), Xiao et al. (2012), García-Torres } \\
\text { et al. (2018), Berktas et al. (2016), Çelik et al. (2015), Sahin et al. (2016), Domingo and Luo } \\
\text { (2017), Karunasena and Amaratunga (2016; 2015), Shibata et al. (2012), Kawamoto and } \\
\text { Kim (2016, 2019), Faleschini et al. (2017), Onan et al. (2015), Wakabayashi et al. (2017), } \\
\text { Askarizadeh et al. (2016), Saffarzadeh et al. (2017), Hu and Sheu (2013), Raila and } \\
\text { Anderson (2017), Poudel et al. (2018), Cheng et al. (2018a), Karunasena et al. (2012), Pham } \\
\text { et al. (2014), Askarizadeh et al. (2017), Sakai et al. (2019), Pramudita and Taniguchi (2014), } \\
\text { Memon (2015), Zhang et al. (2016), Hooper (2019) and Koyama et al. (2016); }\end{array}$ & 33 \\
\hline Tsunami & $\begin{array}{l}\text { Asari et al. (2013), Prasetya et al. (2012), Tabata et al. (2017), Wakabayashi et al. (2017), } \\
\text { Pereira-Portugal and Lee (2016) and Koyama et al. (2016); }\end{array}$ & 6 \\
\hline Hurricane/Typhoon & $\begin{array}{l}\text { Fetter and Rakes (2011; 2012), Habib. et al (2017; 2019), Kim et al. (2018), Lorca et al. } \\
\text { (2017), Fetter and Rakes (2013), Hu et al. (2019), Jiang and Friedland (2016), Thompson et } \\
\text { al. (2011) and Szantoi et al. (2012); }\end{array}$ & 11 \\
\hline Landslide & Tabata et al. (2017) and Wakabayashi et al. (2017); & 2 \\
\hline Flood & $\begin{array}{l}\text { Leader et al. (2018), Pramudita and Taniguchi (2014), Phonphoton and Pharino (2019), Saat } \\
\text { et al. (2016), Tabata et al. (2018), Kim and Kim (2017) and Beraud et al. (2012); }\end{array}$ & 7 \\
\hline Bushfire & Cheng and Thompson (2016), Cheng et al. (2019) and Brown et al. (2011b); & 3 \\
\hline Thunderstorm & Cheng et al. (2018b); & 1 \\
\hline Man-made disaster & Aoki (2018), Noh et al. (2015) and Zhang et al. (2017). & tal: 89 \\
\hline
\end{tabular}

\subsection{Cross tabulation between topic and contribution}

Once a researcher investigates the detail of DWM, a clear question/topic is necessary. Moreover, they need to design a suitable artifact (e.g. theoretical framework, mathematical model and application) as their contribution to analyze a detailed question (Altay and Green, 2006; Galindo and Batta, 2013). Therefore, cross tabulation between topics and contributions was analyzed by the authors of this literature review. Particularly, given that the input data was abstracted from the potential and occurred disasters (Anaya-Arenas et al., 2014), the time phases of the disasters were divided into two categories (e.g. pre-disaster and post-disaster), although the time phases are ambiguous and difficult to be defined (Anaya-Arenas et al., 2014; Gupta et al., 2016). From Table 7, the following results were found: (1) Only one paper addressed the development of DWM in 2011 
(Brown et al., 2011a). After that, there was no literature review to analyze the evolving status. (2) Over 40 percentage of studies (thirty-six) were implemented within a theoretical framework. In detail, strategies, plans and policies of DWM were highlighted in the pre-disaster research. Usually, after a disaster, case studies were used to summarize the experiences of DWM and to discuss the organizational issues. (3) Mathematical models (e.g. mathematical programming and graph theory) were widely adopted to optimize the performance of the DWM system in the post-disaster period. However, similar methods were rarely used in pre-disaster research. (4) Post-disaster research received special attention (69 papers, 84.4\%), while only 12 papers (14.6\%) focused upon pre-disaster waste management. The same proportions were also documented by Crowley (2017). (5) It should be noted that new technologies (e.g. high-resolution aerial imagery and 3D spatial information) is used to estimate the volume of disaster waste (Szantoi et al., 2012; Yoo et al., 2017). 
Table 7. The number of papers reviewed by cross analysis between contribution and topic

\begin{tabular}{|c|c|c|c|c|c|c|}
\hline Item & Topic & Theory & Model & Application & Number & Total \\
\hline- & Outline of DWM & Brown et al. (2011a); & - & - & 1 & 1 \\
\hline \multirow{13}{*}{$\begin{array}{l}\text { Pre- } \\
\text { disaster }\end{array}$} & Strategies, plans and & Crowley and Flachsbart & - & - & 4 & 12 \\
\hline & policies of DWM & (2018), Yusof et al. (2016) & & & & \\
\hline & & and Zawawi et al. (2015, & & & & \\
\hline & & 2018); & & & & \\
\hline & Factors that impact the & Trivedi et al. (2015) and & - & - & 2 & \\
\hline & success of a DWM plan & Crowley (2017); & & & & \\
\hline & Location of DWM site & - & - & Grzeda et al. (2014); & 1 & \\
\hline & Quantities of disaster & - & Tabata et al. (2016); & - & 1 & \\
\hline & debris & & & & & \\
\hline & Capacity building for & Karunasena and Amaratunga & - & - & 2 & \\
\hline & DWM & $(2015,2016)$ & & & & \\
\hline & DWM and its effect & - & Wakabayashi et al. (2017); & & 1 & \\
\hline & Integrated issues & - & - & Askarizadeh et al. (2016); & 1 & \\
\hline \multirow{24}{*}{$\begin{array}{l}\text { Post- } \\
\text { disaster }\end{array}$} & Identification/separation & Shibata et al. (2012); & - & Jiang and Friedland (2016), & 4 & 34 \\
\hline & of disaster debris & & & Pham et al. (2014) and & & \\
\hline & Estimation of disaster & Tabata et al. (2018); & Poudel et al. (2018); & Koyama et al. (2016), & 8 & \\
\hline & debris & & & Szantoi et al. (2012), & & \\
\hline & & & & Thompson et al. (2011), & & \\
\hline & & & & Garcia-Torres et al. (2017), & & \\
\hline & & & & Yoo et al. (2017) and & & \\
\hline & & & & Benjamin et al. (2011); & & \\
\hline & Dispersal of disaster & - & & Prasetya et al. (2012); & 1 & \\
\hline & debris & & & & & \\
\hline & DWM and its effect & Phonphotopn and Pharino & Cheng et al. (2018a; 2018b) & Faleschini et al. (2017); & 11 & \\
\hline & & (2019), Aoki (2018), Raila and & and Tabata et al. (2017); & & & \\
\hline & & Anderson (2017), Noh et al. & & & & \\
\hline & & (2015), Caniato et al. (2016), & & & & \\
\hline & & $\begin{array}{l}\text { Beraud et al. (2012) and Baek } \\
\text { et al. (2016); }\end{array}$ & & & & \\
\hline & Treatment (option) of & Brown and Milke (2016); & Sasao (2016); & Portugal-Pereira and Lee & 6 & \\
\hline & disaster waste & & & (2016), Regattieri et al. & & \\
\hline & & & & $(2016,2018)$ and Leader et & & \\
\hline & & & & al. (2018); & & \\
\hline & Allocation of resources & - & Fetter and Rakes (2011, & - & 2 & \\
\hline & (e.g. facility) & & 2013); & & & \\
\hline & Location of facility, & - & Wang et al. (2019); & Cheng and Thompson & 2 & \\
\hline & temporary storage site & & & (2016); & & \\
\hline & and processing site & & & & & \\
\hline
\end{tabular}


(Continued)

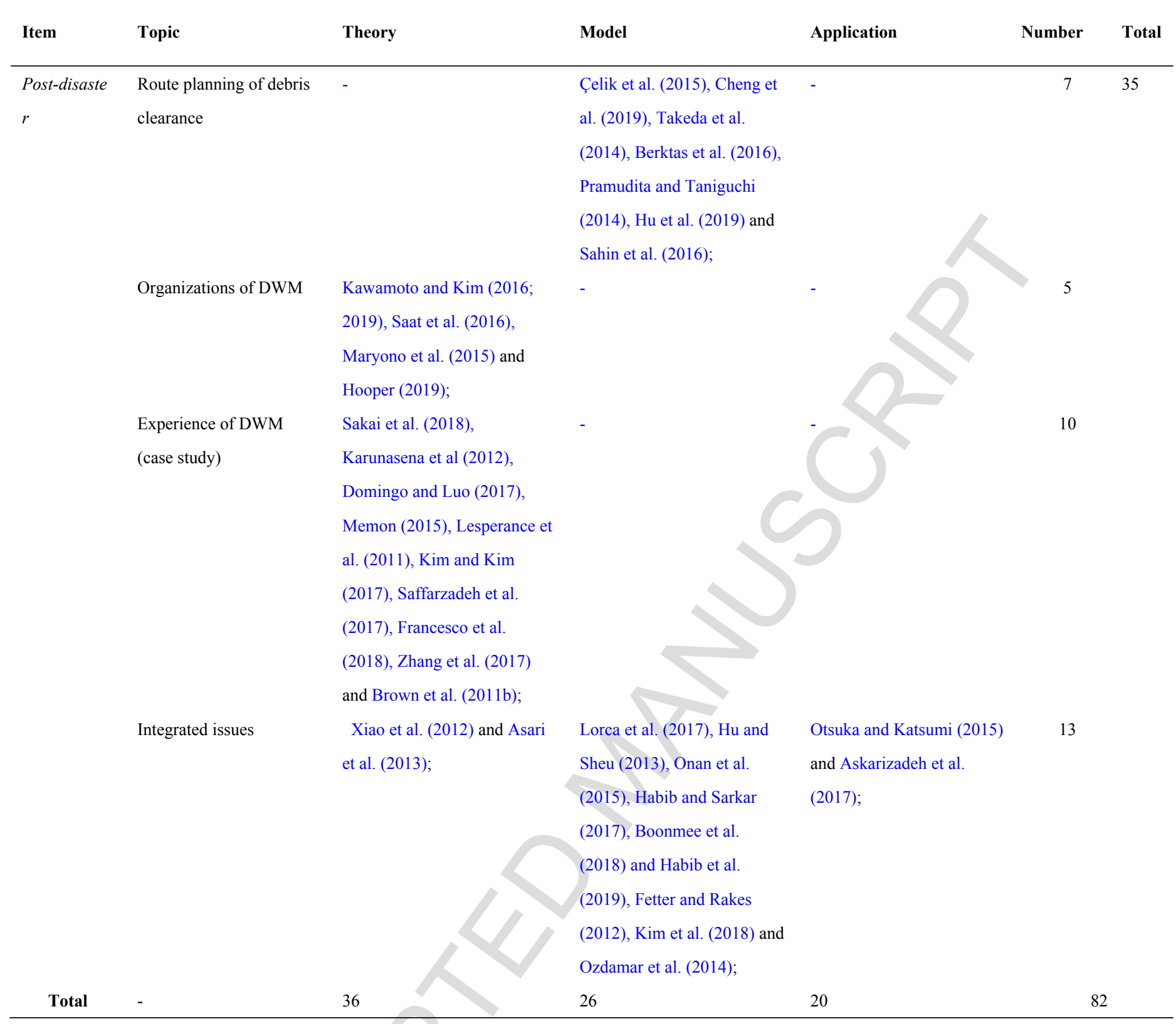




\section{Results of the thematic analysis}

Since 2011, there were no reviews to update the development of DWM research and to analyze whether the research gaps identified by Brown et al. (2011a) are addressed or not. Therefore, building upon their work, the structure of the thematic analysis was organized from nine aspects: planning, waste, waste treatment options, environment, economics, social considerations, organizational aspects, legal frameworks and funding, to compare our findings with theirs. Especially, their research gaps were listed in front of each subsection. The comparison between research gaps and the recent studies were discussed at the end of this section.

\subsection{Planning}

Research gaps: (1) The existing plans focused on technical interventions but ignored the guidance on decision making in different disaster contexts; (2) There were no guidance documents that could be readily applied to other developed countries, especially regarding the establishment of effective organizational, financial and legal structures for DWM; (3) Plans of DWM seldom existed in developing countries.

Based on the documents with regard to "Planning for disaster debris" and "Planning for natural disaster debris" (USEPA, 1995; USEPA, 2008), planning generally are associated with the overview, events and assumptions, debris collection strategy, roles and responsibilities, debris management sites and contracted debris operation (Corwley and Flachsbart, 2018). As Crowley (2017) noted, pre-disaster plans contributed to rapid waste clean-up. However, the lack of enforced plan was commonly identified as a capacity gap in DWM practice, in developed countries (Sakai et al., 2019; Domingo and Hao, 2017) and developing countries (Karunasena et al., 2012; Zawawi et al., 2018).

To analyze the reason why such a conflicting situation commonly existed, Brown et al. (2011b) did an interview with disaster managers. They analyzed three possible reasons as: the perceived difficulty in planning for the unknown, the low probability of such large-scale disasters and the success of DWM practice (implemented without a plan). Similarly, Maryono et al. (2015) identified the top four factors which impacted the intentions of preparing for DWM, such as awareness of the difficulty with regard to running a program of reduction, reuse and recycling, awareness of cooperation with other stakeholders, concerns about previous experience as well as awareness of the insufficiency of facility. 
Conclusion: In recent year, the planning of DWM is still limited in both developed and developing countries, and there is no obvious development in planning for DWM. Thus, research gaps identified by Brown et al. (2011a) is not well covered. Moreover, planning for DWM seems not received by disaster managers in practice, but the reason why the situation exist is not clear.

\subsection{Waste}

Research gaps: (1) The nature of disaster waste was widely investigated from the perspective of disaster type. However, other viewpoints (e.g. the nature of the built environment being impacted, the level of hazards and ability to recycle) were rarely discussed; (2) The method to measure, calculated and estimated the waste quantities was not explicitly stated, although lots of authors reported the data of waste quantities; (3) Although a few estimation methods may be transferred between contexts, actual waste quantities were less likely to be transferred. In other words, the general method to estimate waste in different disaster contexts was absent; (4) Compared with the estimation method retrospectively quantified disaster waste following disaster events, the evaluation models for predicting the quantities of waste were limited.

\subsubsection{Waste composition and separation}

Given that the nature of disasters is closely associated with disaster contexts, the type of disaster is widely adopted for separating waste at the early stage of DWM research. For example, C\&D waste received an increasing attention by researchers interested in earthquake waste management (Domingo and Luo, 2017; Karunasena et al., 2012), while vegetative waste or green waste was widely discussed in the case of hurricane waste management (Lorca et al., 2017; Thompson et al., 2011). The large number of studies concentrated on waste which was directly caused by the disasters, especially earthquake caused waste.

However, the indirect impact of disasters on waste management was rarely reported in the papers, although the corresponding waste management is also of great significant. For example, waste related to evacuation shelters (e.g. plastic packaging waste of food and water) was highlighted as an important issue in the Great East Japan Earthquake (Asari et al., 2013). Besides, electronic waste received a special attention because of the high risk of health and environmental consequences, although the proportion of electronic waste is very small (Leader et al., 2018). Moreover, in the period of humanitarian aid, healthcare waste was treated as a separate category due to the hygiene concerns (Caniato et al., 2016). 
Although the nature of disaster waste was well identified by disaster type, the nature of the building environment was also called for future research (Brown et al., 2011a). Due to differences of geographical location (e.g. internal and coastal area) and urbanization level (e.g. industrial and urban), significant differences were observed in the types and quantities of disaster waste, and, also, in the management approach (Francesco et al., 2018). Therefore, it is necessary to analyze the nature of disaster waste from different perspectives. After a widely reading of papers, the method of waste separation was concluded from two viewpoints regarding affected area and level of hazards.

\section{Affected areas.}

Given the main differences of population densities, building structures (e.g. masonry and masonry-frame structures are typical in rural area, but concrete-frame structures are common in urban area) and lifestyles, $\mathrm{Hu}$ and Sheu (2013) and Xiao et al. (2012) respectively investigated the urban- and rural- generated waste in Wenchuan earthquake, and they suggested the considerable different solutions for Chinese DWM practice. Tabata et al. (2017) identified two types of waste (e.g. costal- and inland- generated waste) and discussed the diverse solutions to reduce the negative impact of environment and economy.

\section{Level of hazards.}

Given that exposures to hazardous wastes results in high risk of public health, managing such materials is of great significant, especially in disaster contexts (Zhang et al., 2017; Kim and Hong, 2017). For example, (1) Wood is widely used for construction, and it is often treated by hazardous materials (e.g. lead, arsenic and creosote) to protect wood from fungi and termite attack (Dubey et al., 2007; Baek et al., 2016). Unfortunately, once a disaster occurs, the damage to such wood will lead to a negative impact on ecological sustainability. To achieve the safe management of such a hazardous material, Kim and Hong (2017) analyzed the solutions in term of quantification of waste volumes, technologies and policies for safe management or disposal of the waste. (2) Zhang et al. (2017) noted that the frequency of the occurrence of man-made disasters (e.g. nuclear events and hazardous materials spill) pose significant challenges to human beings. They critically investigated the effectiveness of environmental management systems which are based on the case of the Tianjin warehouse explosion. The explosion occurred on 12 August 2015 resulted in 165 dead and more than 800 injured people. Fortunately, the environment was well monitored and controlled by sound management of toxic chemical and post-disaster solid waste. 
Similarly, Lesperance et al. (2011) argued that the recent DWM plan did not address the management of waste containing chemical, biological and radiological materials. They identified numerous challenges in properly managing the related wastes (e.g. anthrax waste). (3) Humanitarian aid and health care are inextricably linked (Raila and Anderson, 2017), and the frequent exposure of health-care waste poses potential public health risks and aggravates the psychological burden of victims. However, health-care waste management is a big challenge for low- and middle- income countries owing to obsolete technology and shortage of funds (Caniato et al., 2016). To reduce the potential risk of public health and to minimize the negative impacts on climate change, Caniato et al. (2016), Raila and Anderson (2017) and Zhang et al. (2017) discussed the related policies, estimated the waste volumes and designed the DWM system.

\subsubsection{Waste quantities}

Risk prevention and reconstruction planning depend on the development of methodologies with respect to waste quantities (Garcia-Torres et al., 2017). Moreover, under- and over- estimation of waste volumes would result in a high level of costs during the period of DWM (Lorca et al., 2017). Therefore, accurate prediction/estimation of waste volumes is helpful in performance improvement and cost reduction. Based upon the review of relevant papers on waste quantification, two types of methods are used: a. mathematical model, b. technology-based analysis tool, to estimate the waste volumes.

The mathematical models use mathematical notation and logic to describe the relationships among types of disasters, severity of the disasters (e.g. magnitudes of earthquake and strength of hurricane), type of wastes (e.g. buildings and trees) and characteristic of disaster waste (e.g. density of buildings/trees/population, tree height, location of buildings/forests and age of buildings), and then to use the inventory data, so as to estimate the waste volumes (Pham et al., 2014; Askarizadeh et al., 2017; Askarizadeh et al., 2016; Poudel et al., 2018; Thompson et al., 2011; Garcia-Torres et al., 2017). Such a method can be used not only to estimate the data of waste volumes in the aftermath of a disasters, but also to predict the potential waste generation in the period of pre-disaster (Tabata et al., 2016; Tabata et al., 2018).

A second type of approach to estimate the quantities of diverse types of wastes associated with disasters are automatic detections and estimations of waste volumes analyzed by high-resolution satellite and aerial imagery (Pham et al., 2014; Jiang and Friedland, 2016; Koyama et al., 2016; 
Szantoi et al., 2012; Saffarzadeh et al., 2017). This method provided an quick evaluation of damages, especially in a large areas and the collapsed infrastructure which may not be detected at ground level (Pham et al., 2014). However, the accuracy of aerial imagery weakened by the difficulty of distinguishing the shadow between collapsed buildings/trees and other urban features (e.g. fences). Additionally, the shadows of standing trees and unaffected buildings could also be inaccurately assessed as damage due to their shapes and colors (Pham et al., 2014; Szantoi et al., 2012). Moreover, when the method was used to estimate tree debris, it was hard to identify the downed branches and the small diameter trees which also contributed to total waste quantities (Szantoi et al., 2012).

\subsubsection{Waste management systems}

Given that systems for management of disaster wastes are always difficult, time-consuming and expensive, the modeling of DWM systems is of urgently needed (Cheng et al., 2018). As Lorca et al. (2017) noted, DWM operation are regarded as humanitarian logistics activities. The system of DWM could be described as a reverse logistics system according to $\mathrm{Hu}$ and Sheu (2013) who explored the traditional problem of logistic management (e.g. location of temporary storage site/processing site, transportation and route planning, as well as allocation of resources), which provides quantitative decision-support tools for DWM practice from a reverse logistical perspective. In general, such systems were formulated by a mathematical programming model which included objective functions, constraints and decision variables (Hu and Sheu, 2013; Habib et al., 2019; Fetter and Rakes, 2012).

Firstly, the selection of temporary storage sites and processing sites is the main location problem in the period of DWM (Wang et al., 2019; Cheng and Thompson, 2016). In detail, the decision variable is whether to establish a waste processing site in location, a or b or c. Certainly, allocation of facilitates must be simultaneously considered in making the waste processing location decision (Habib and Sarkar, 2017). That decision must also be used in allocating human resources and vehicles, storage of the wastes as well as processing of them.

Decisions also need to be made about if the wastes are to be incinerated, landfilled, or recycled (Boonmee et al., 2018). Generally, the support models are designed to help to achieve the goal of cost minimization, and they are also limited to constraints based on the actual disaster contexts. Cheng and Thompson (2016) summarized 55 constraints from the perspectives of environmental, social-cultural and economic-engineering with special foci upon: distance from surface water, land 
use, distance from residential areas, land slopes and roads, which are the top five criteria considered in previous research.

Secondly, given the distributed characteristics among the affected areas, temporary storage sites, processing sites and markets, an effective routes planning contributes to implementation of disaster operations management (Sahin et al., 2016; Takeda et al., 2015; Pramudita and Taniguchi, 2014). Route planning refers to performing analyses about which routes to use for transportation, to collect and to transport wastes from certain areas in the shortest time. Thus, minimization of travel and waiting time are integral to planning the routes. Also, the total time will be affected by the priority of critical nodes (e.g. school and hospital), the busy degree of roads (e.g. daytime and nighttime), the incomplete information of roads and road blockages (Berktas et al., 2016; Hu et al., 2019; Celik et al., 2015; Sahin et al., 2016). Particularly, the potential damage to roads was considered into the design of route planning, which addresses the gap with respect to the ignorance of stochastic behavior in disaster operations management.

Although many researchers investigated the optimized DWM system in a certain disaster context, uncertainties and risks were not well considered in the design of waste management system. To deal with this problem, uncertainties and risks influence the reliability of DWM systems which must be tested by the relationships between system capacity and waste generation (Cheng et al., 2018a; Cheng et al., 2018b). Additionally, several authors emphasized the importance of the roles of simulations of different waste management scenarios, which can be used to provide decision-support inputs for improving the resilience of DWM systems (Kim and Kim, 2017; Kim et al., 2018).

Conclusions: (1) Compared with the previous studies regarding waste separation, authors of recently published papers are beginning to address the impacts of disaster contexts (e.g. affected areas and the types and levels of hazards) on waste management, although general studies are still common; (2) The measurement methods of waste volumes were highlighted and reported on by many researchers. The waste measurement methods can be divided into mathematical modeling and technology-based analysis approaches. It should be noted that GIS technology (e.g. high -resolution satellite and aerial image) is widely used in estimation of quantities and locations of post-disaster wastes. However, the prediction of disaster waste is still absent. In addition to that, tools to detect the dispersal of waste is limited (Prasetya et al., 2012), especially tree debris in the context of hurricanes and wastes in the entire coastal area of affected regions; (3) This review of DWM systems 
contributes highlighting how to improve DWM decision-making.

\subsection{Waste treatment options}

Research gaps: (1) Location and management aspects of temporary staging sites should be investigated by more future research; (2) There was no quantitative method to assess the preparedness, feasibility and effectiveness of waste recycling; (3) Waste-to energy was an emerging topic which received some attention but there was no review of the success of these initiatives; (4) The practice of open burning was not specially analyzed after a disaster; (5) The actual environmental impacts of land reclamation and disaster disposal sites were absent.

Due to the consideration of cost-efficiency, environmental protection and minimization of psycho-social impact, waste treatment options are closely associated with the efficiency of disaster responses and disaster recoveries (Tabata et al., 2017; Lorca et al., 2017). Based on the classification developed by Brown et al. (2011a), waste treatment was analyzed from fives aspects: a. temporary storage, b. recycling, c. open burning, d. landfilling and e. waste-to-energy.

\section{Temporary storage}

Temporary storage was one of the most important approaches for the management of disaster wastes. Such storage often serves as an intermediate point to store wastes which will be transported to incineration plants, recycling areas and landfill sites. In order to cope with the challenge of considerable amounts of waste in a large-scale disaster, two levels of temporary sites can be established (Tabata et al., 2017; Sakai et al., 2019).

In detail, the primary 'temporary storage site' must serve to store wastes for a limited time and they often located near the affected areas. In contrast, the secondary sites must be designed to store large amounts of waste in locations further away from the affected areas, the residential zones and the pollution-prone district (FEMA, 2007). It is important to note that decisions about the selection of locations of temporary, secondary and other waste management facilities, are influenced by many constraints, which are addressed in the subsection of waste management systems.

\section{Recycling}

As an eco-friendly waste treatment option, recycling is beneficial for recovery of economic value from recovery of materials, for recovery of energy, for job creation and for reduction of landfill space used (Brown and Milke., 2016) and can result in cost reductions (Fetter and Rakes, 2012). The papers by Regattieri et al. (2016), Regattieri et al. (2018) and Faleschini et al. (2017) provided data 
on successful experiences of recycling materials from disaster-related solid wastes. Unfortunately, few authors documented that recycling is widely used in DWM practice.

For example, due to the lack of professional knowledge (Karunasena et al., 2009) and lack of sufficient funds (Karunasena and Amaratunga, 2015), large quantities of reusable and recyclable materials continue to be disposed of in landfills and or via incineration, especially in developing countries (Brown and Milke, 2016). Besides, over aggressive recycling can be counterproductive, and can increase the total costs (Fetter and Rakes, 2012).

Consequently, it is necessary to design a quantitative method to help disaster waste managers to decide when to recycle and how to perform a well-functioning recycling system. Authors Brown and Milke (2016) provided guidance to waste managers by analyzing the feasibility of successful recycling (e.g. volume of waste, degree of mixing of waste, human and environmental health hazards, areal extent of waste, community priorities, funding mechanisms and regulations) and effectiveness of recycling in a qualitative way.

\section{Open burning}

As Brown et al. (2011a) noted, open burning was strictly prohibited in some countries and regions, which resulted from the bad impacts of toxic gases on the environment and upon public health. However, many authors stated that incineration had a greatly positive impact on performance improvement of DWM, especially in a time-pressure situation (Asari et al., 2013; Sasao, 2016). Also, after a comparation analysis among several waste treatments approaches, more incineration plants were suggested to achieve the rapid disaster response actions (Lorca et al., 2017; Kim and Kim, 2017).

\section{Landfilling}

Thanks to the efficiency of disposing of disaster wastes (e.g. cost reduction and rapid disposal), landfilling has been widely adopted by disaster managers, especially in developing countries. The application of such treatment relies on a suitable space (e.g. land near to lakes and rivers may not be used for landfills), landfill capacities, safety of materials, classification treatment and well-planned project of DWM (Lorca et al., 2017).

\section{Waste-to-energy}

This approach can be an eco-friendly waste treatment method which produces liquid fuels (e.g. FT-Diesel) and electricity with the help of advanced technologies (e.g. Combined heat and power, 
Gasification and Fischer-Tropsch), although high costs and the accessibly of the advanced technology should be considered (Portugal-Pereira and Lee, 2016). The application of high-quality waste-to-energy systems in Japan provided successful examples that confirmed their benefits for management of disaster-related wastes as well as on-going management of municipal wastes. Also, such cases address some of the gaps identified by Brown et al. (2011a).

Conclusion: In this subsection, the research gaps (e.g. no specific case of open burning and waste-to-energy, ignorance of environmental effects of landfill, as well as the limited research with regard to the location of temporary storage site) what were identified by Brown et al. (2011a) were extensively and effectively addressed by Portugal-Pereira and Lee (2016), Tabata et al. (2016) and Wakabayashi et al. (2017). However, the quantitative method to assess the feasibility and effectiveness of waste treatment was not adequately addressed in any of the papers include in this literature review.

\subsection{Environment}

Research gap: No author attempted to quantify the environmental impacts of altering peace-time waste management standards to manage disaster wastes.

Disasters and environment are inextricably linked (Brown et al., 2011a). Disaster operations management is closely associated with the environment, especially in managing the disaster waste (Galindo and Batta, 2013). For example, carbon emissions from transportation (Tabata et al., 2016), pollution generated from incineration and landfilling (Wakabayashi et al., 2017), the risks of waste exposure (Hu and Sheu, 2013) and environmental effects of temporary storage and disposal (Lorca et al., 2017) were considered as environmental aspects for which there are urgent needs to minimize the negative impacts of the disaster -related wastes and to therefore, to protect humans and the environment.

To provide useful guidance for decision-making, environmental aspects were generally tested by three methods. Firstly, based on life cycle assessment, indicators concerning $\mathrm{CO}_{2}, \mathrm{SOx}, \mathrm{NOx}$ and PM emissions were used to test the environmental effects of various activities (Wakabayashi et al., 2017; Tabata et al., 2016). In research published by $\mathrm{Hu}$ and Sheu (2013), the author used risk analysis to examine the environmental effects of waste collection, processing, transportation and disposal. Similarly, Lorca et al. (2017) investigated the environmental effects via environmental costs which were estimated by local governments. Based on their study, environmental effects can be 
measured, and are compared with the economic effect and psychological cost, which provided an effective decision-support tool for balancing the conflicts among economic, environment and psychological burden. Obviously, those two methods were based upon a strong subjectively, although they seemed to be practical for DWM practice within a limited time.

Conclusion: Environment effects were effectively estimated by different methods. Unfortunately, there is still no research which investigates the environment impacts of changing peace-time waste management standards and practices to improve management of disaster-related solid wastes.

\subsection{Economics}

Research gap: The economic impacts (both direct and indirect) of DWM programs was limited.

Cost efficiency is always highlighted in managing disaster waste. Direct economic effects (Fig. 2) are related to the process of DWM (e.g. waste identification, collection, separation, storage and transportation), and the costs are generally captured within transportation costs, classification costs, storage costs, treatment costs, disposal costs and potential returns from recycling (Lorca et al., 2017; Hu and Sheu, 2013; Fetter and Rakes, 2012; Tabata et al., 2016), to measure and optimize the total direct costs of DWM. Apart from direct economic effects, the fixed costs of opening a temporary site were also considered (Lorca et al., 2017; Wang et al., 2019). 


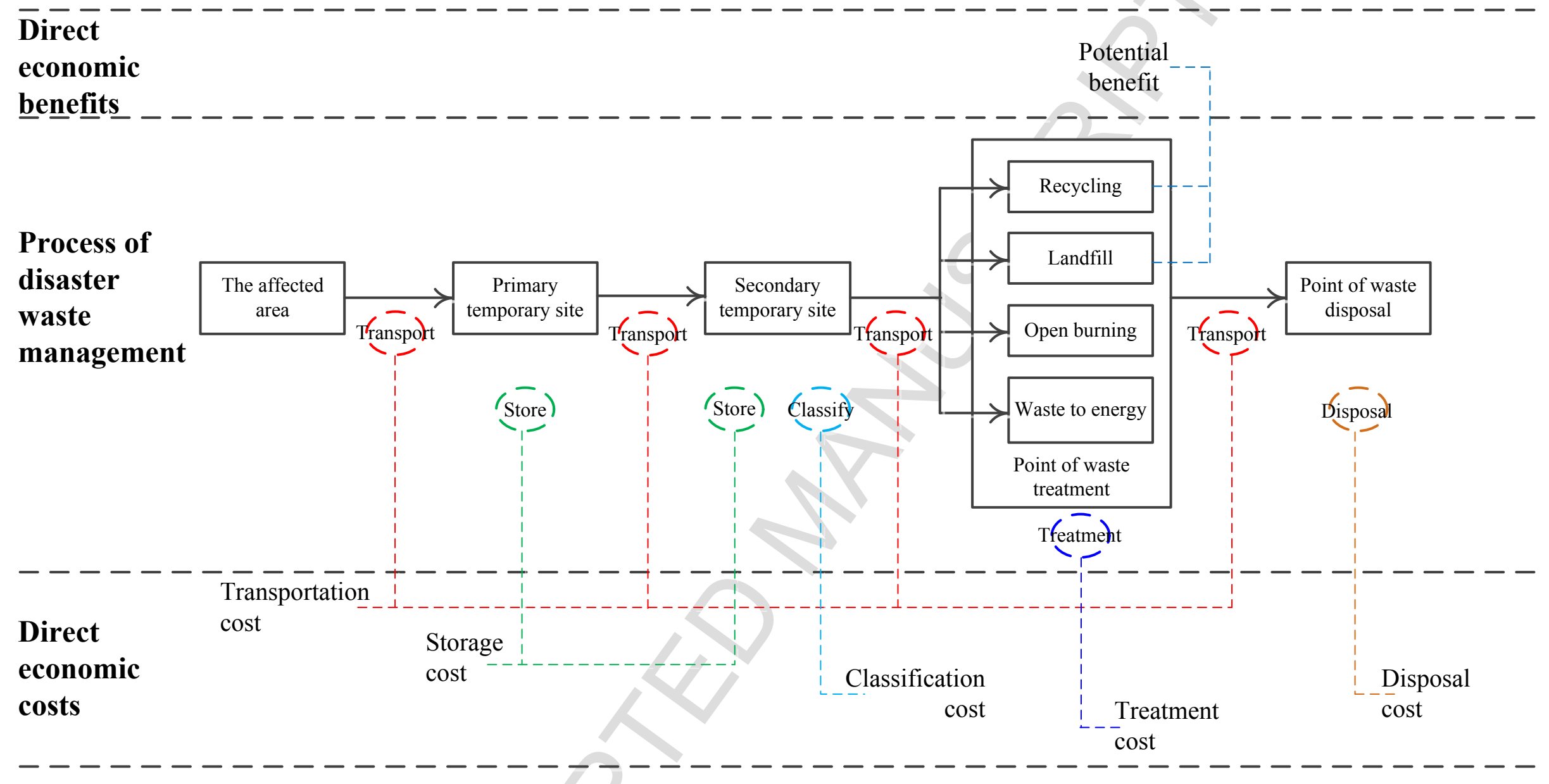

Fig. 2 Direct economic effect of DWM which should be considered in the DWM programs 
Indirect economic effects are also of great significance, which can be divided into costs and returns. On the one hand, the sustainable development of affected area is always influenced by the indirect costs regarding disruption of critical infrastructure, risk to public health, delays of waste disposal and rebuilding, as well as road blockages. On the other hand, job opportunities (Habib et al., 2019), development of new technologies (Portugal-Pereira and Lee, 2016) as well as expansion of business scope of transportation enterprises (Hu and Sheu, 2013) were regarded as indirect economic returns.

Conclusion: Compared with the previous studies, direct economic effects were well measured, while the measurements of indirect economic effects were still limited.

\subsection{Social considerations}

Research gaps: Research on social considerations (both qualitative and quantitative) was limited, especially the impact of DWM on community recovery and a post-disaster community behavior on the functioning of the program of DWM.

Motivated by $\mathrm{Hu}$ and Sheu (2013) and Brown et al. (2011a), the social considerations were discussed from the perspectives of the victims, employees and the communities.

\section{Victims}

Rapid post-disaster waste cleanup is closely associated with psychological recovery because of the awareness of available social support, which is more important than the reconstruction of building and infrastructure (Hu and Sheu, 2013). In detail, anxiety and stress accumulate within societies after long time waiting periods, which results in a deep sense of frustration due to wasted time and uncertainty about when something will be done to 'solve' the problems.

\section{Employees}

The authors of one article addressed employees, although many workers, managers and volunteers participated in waste cleanup processes. The social consideration was captured by the anxiety of vehicle drivers and debris treatments workers (Hu and Sheu, 2013). The worker anxiety was different from the negative emotions of the victims, more broadly, who had to wait and wait for service systems to be established and implemented.

\section{Communities}

The potential risks to the public health was highlighted by residents near to waste disposal sites, especially those sites responsible for managing hazardous materials. By means of oxidative stress 
biomarkers, Noh et al. (2015) verified that there was a significant relation between long-term cleanup and threats to human health. Similarly, waste generated from the Fukushima nuclear exposure incident was rejected by numerous residents due to consideration of safety, especially families with children four years old or younger (Aoki, 2018). Indeed, an inappropriate disposal of disaster waste may result in resistance of residents. But if done properly (e.g. guarantee the safety of waste disposal, increase the perceived benefit, improve the credibility of the government and communicate with residents) (Aoki, 2018; Brown et al., 2011a), the operational rate of DWM (especially quality change) can be significantly improved by a cooperative network among the community's members (Kawamoto and Kim, 2016).

Conclusion: The ignorance of post-disaster community behavior is well addressed in a qualitative way. However, how to quantitatively measure the social considerations is still limited, although $\mathrm{Hu}$ and Sheu (2013) employed the waiting time to test the emotions of anxiety and stress.

\subsection{Organizational aspects}

Research gaps: (1) The organizational structures were not critically discussed in literature; (2) No author critically investigated what factors should be considered in the organizational design of the physical works associated with disaster waste program; (3) The effect of pre-arranged contracts and rates with contractors were absent; (4) There was little data on suitable GIS technologies and their effectiveness.

In this context, 'organization' is defined as human resources to manage the activities of DWM. Not only professional groups (e.g. government, non-profit organization and military) but also individual teams (e.g. volunteers) are involved (Karunasena and Amaratunga, 2016; Kawamoto and Kim, 2016; Kawamoto and Kim, 2019). Regarding organizations, no single organization is capable of addressing the uncertainties of disasters and being able to provide the coordinated efforts required to aggregate them. If not addressed properly, the suffering of the affected populations and the losses of property may be increased and prolonged (Dubey and Altay., 2018). Not surprisingly, linkages and collaborations (focus on building partnership with external organizations) as well as communication and coordination (concentrate on internal coordination) were highlighted (Karunasena and Amaratunga, 2016) in the process of DWM. However, the method regarding how to achieve the coordination (e.g. coordinated network and coordination mechanism) was not addressed. 
Moreover, Brown et al. (2011b) contended that the roles and responsibilities of organizations were unclear as a result of the temporary establishment of coordination, especially when the pre-disaster plan was absent. A similar viewpoint was presented by Hooper (2019) who stated that the establishment of professional organization was necessary.

Conclusion: Organizational aspects are still not well discussed by researchers.

\subsection{The legal frameworks}

Research gap: The existing regulations were often unclear to what degree and in what circumstance legal or regulatory relaxations are acceptable. In other words, the legislation was inconclusive and gave no guidance on future use of legal waivers.

Based on this literature review, the recent development of legal framework can be divided into two types. On the one hand, the unavailability of enforceable legislation is often highlighted in practice of DWM, especially in developing countries (Karunasena et al., 2012; Yusof et al., 2016; Memon, 2015). On the other hand, in developed countries and a few developing countries, the official documents were composed by governments, to guide the management of DWM, such as "Planning for Disaster Debris", "Planning for Natural Disaster Debris" and "Public Assistance: Debris Management Guide", "Guidance of Disaster Debris Management", "Japan Society of Material Cycles and Waste Management" and "National Solid Waste Management Strategy" (USEPA, 1995; USEPA, 2008; The Central People's Government of the People's Republic of China, 2008; Crowley and Flachsbart, 2018; Asari et al., 2013).

Compared with the results of Brown et al. (2011a), there has been progress in the development documents pertaining to the legal frameworks. However, the documents were designed to serve to provide guidance for DWM practice, therefore, the requirements stated in the documents were not legally enforceable (USPEA, 2008; The Central People's Government of the People's Republic of China, 2008).

Additionally, the documents, due to their ambiguous statements, they played limited roles in practice. For example, given the conflicts between environmental protection and cost reductions, situations for when the adoption of open burning is appropriate led to difficulties of decision-making (Wakabayashi et al., 2017; Lorca et al., 2017; Karunasena et al., 2012). Also, it was difficult to select the optimal location of waste disposal sites because of challenges associated with environmental justice or injustice (Allen, 2007). As Brown et al. (2011a) reported, the ambiguous statements may 
be caused by a lack of adequate details and to cases in recent documents, which resulted in managerial confusion.

Conclusion: Although there was increasing attention by authors of papers reviewed for this review, the establishment of legislation, the related regulations should be expanded, clarified and enforced within more detailed cases.

\subsection{Funding}

Research gap: The effective mechanisms (private, public and insurance) for funding DWM in different disaster contexts was absent.

Funding plays a fundamental role in allocation of resource during disaster contexts, although humanitarian aid was usually treated as non-profit activities. Karunasena et al. (2009) and Karunasena et al. (2012) argued that the sufficiency of funds was closely associated with the acquirement of the required technology and equipment, and it determined the difference between successful and failed DWM (Saat et al., 2016). However, the lack of fund was generally identified as a major barrier (Memon, 2015) because of the conflicts between fund-provider and fund-receiver. On the one hand, for fund-receivers, they often complained that there was no strict law to protect their financing behavior, which leads to their inability to obtain sufficient funds within a short time (Fetter and Rakes, 2012). Under such circumstances, they usually have to choose the cost-efficient treatment (e.g. open burning and landfill) to clean up disaster waste. On the other hand, fund-provider contended that they were willing to provide more funds, so long as the receiving organizations provide a detailed implementation plan. Unfortunately, the detailed plan (e.g. planning for recycling) was not provided by the anticipated fund-receiver (Crowley and Flachsbart, 2018).

Conclusion: Although funds were identified as a big challenge for DWM, the effective financial mechanism was still absent.

\subsection{Summary}

To answer whether the research gaps identified by Brown et al. (2011a) were covered or not, the contents of Table. 8 present the detailed results of the literature reviewed for this article.

Following Table. 8, Results indicated that there are no obvious changes or developments in the field of DWM, although a few research gaps have been well addressed, such as waste separation, waste quantities, case study of incineration and waste to energy, directly economic effect, social considerations as well as application of GIS technologies. 
Table. 8 The detailed results of the literature reviewed for this article

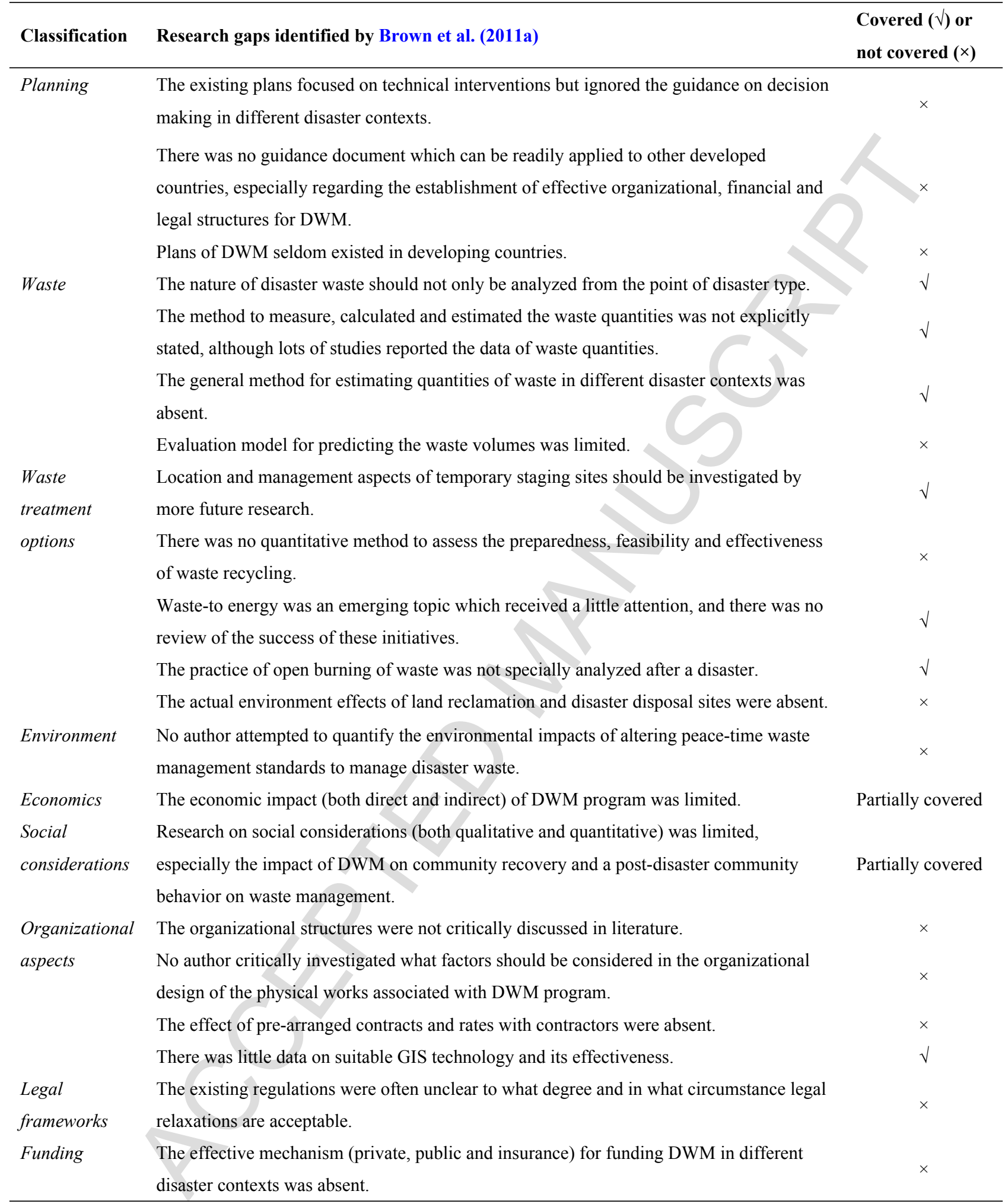

\section{Discussion}

The authors of this literature review analyzed gaps in knowledge highlighted by Brown et al. (2011a), to determine which have been addressed in the 82 papers selected for this literature review and which gaps still need to be addressed by future research. 
In brief, much progress has been made but many gaps still exist as discussed in the following sections.

\subsection{Planning}

Based on our reviewing, the desire of preparing a plan is not high in practice (Brown et al., 2011b), although the importance of establishing a plan was suggested by lots of researchers (Zawawi et al., 2018; Brown et al., 2011a; Memon, 2015). According to Brown et al. (2011b) and Maryono et al. (2015), such a phenomenon may be caused by the success of DWM practice (implemented without a plan) and the impact of rich experience on successful operations. As Crowley (2017) identified, a well-established plan was beneficial to achieve the programmatic goals (e.g. implementing a recycle plan and removing more waste per day), but disposal cost could not be reduced by a pre-disaster waste management plan. Under this circumstance, it is necessary to reconfirm the positive relationship between plans and performance improvement.

\subsection{Waste}

As Table 6 presented in subsection 3.4, general studies and earthquake cases were widely discussed in recent years, which provides considerable amounts of knowledge and experience for researchers and practitioners. However, it seems not beneficial to develop the field of DWM research.

On the one hand, disasters are so different, and general studies may not fit all (Gupta et al., 2016). In other words, DWM relies on disaster context, which requires a specific approach to manage disaster wastes. On the other hand, the ignorance of other types of disasters (e.g. hurricane and man-made disaster) results in inadequate research of DWM. Deconstruction of brick- and concrete-based materials is the main work of DWM after an earthquake, which indicates that such activities will last for a long time. Unfortunately, the related knowledge, experience and model cannot be well applied in time-pressure situations. For example, Super Typhoon Mangkhut landed in Shenzhen and Zhuhai in China, it caused a large number of trees to be blown down by the wind on September 16, 2018. In this context, road blockage caused by fallen trees that had to be transported in a short time, has a different urgency than the long-time waste management of building wastes after earthquakes. Consequently, it is necessary to investigate the specific method/model for managing wastes in different types of disasters.

Differing from the previous studies focusing on separation methods which are based on diverse 
disaster types, several methods to classify disaster wastes were developed (e.g. the affected areas, the level of hazards and the ability to recycle the wastes). The authors of these studies did a good work in separation of waste which was directly caused by disasters. However, investigation on the waste which was caused by indirect effects was very limited (e.g. medical waste and waste from evacuation shelters) (Asari et al., 2013; Raila and Anderson, 2017). To our knowledge, few scholars used qualitative method to discuss the innovative solutions for reusing packaging waste materials (Regattieri et al. 2018), the data-based theoretical framework for managing healthcare wastes (Sahni et al. 2018) and management of plastic bottle and filter water (Wang et al., 2019). The authors of following paper mainly focused on collection and disposal of disaster wastes but ignored the transportation of such wastes. In this regard, the main differences between other types of waste and the two wastes related to the logistics system (e.g. reverse logistics system is common in managing waste directly generated by disaster, while the transportation of medical waste refers to the practice of close-loop logistic supply chain). In detail, relief materials (e.g. medical, food, water and tent) are transported into the affected area. Then, when the relief materials are used, the related wastes (e.g. medical waste, plastic bag and bottle) must be transported from the affected area to other processing site. In this process, a complete close-loop supply chain is composed of the input of relief materials and the output of the related waste.

As Caniato et al. (2016) noted, uncollected waste (especially healthcare waste) exposing in the air for a long time poses a potential public health risk. Besides, optimization of logistic system can accelerate the speed of clean-up (Hu and Sheu, 2013). Thus, it is valuable for scholars interested in supply chain management to discuss the related issues in such a context.

Quantification of waste received a growing attention by many researchers, but the accuracy of estimation model and the prediction of waste quantities poses challenges for future research. On the one hand, under- and over-estimation of waste quantities can result in problems in estimation of costs and benefits (Lorca et al., 2017), especially post-disaster waste estimation. Based on the existing studies, the accuracy of estimation model (both mathematical model and technology-based analysis tool) was significantly influenced by the completeness of inventory data and the quality of imaging processes. Thus, the degree of accuracy should be increased from two perspectives.

On the other hand, the lack of accuracy of the predictive estimation model may be caused by the lack of high technology. The prediction of waste volumes closely related to the prediction of disaster 
contexts, the potential damage to social system and the characteristic of system, which needs to collect the related information and then to analyze it. To achieve this goal, Misra et al. (2018) proposed an IoT-based system to automatically monitor maximum waste level of bin and hazardous waste. It is helpful for practitioner to dynamically acknowledge the risk of waste management process and discussing the prevention strategies before the occurrence of an event.

Inspired by them, the IoT-based system can be used for the prediction of disaster waste. In detail, not only waste bin but also infrastructures (e.g. buildings and trees) can be combined by sensors and intelligently monitored by cloud technologies. Once a disaster occurs, the quantities of collapsed buildings and fallen trees can be predicted by simulation of disaster contexts, and it beneficial to decision making. Consequently, it is necessary to further study the predictive method of waste volumes based on IoT technology.

\subsection{Waste treatment options}

Based on the literature review for this article, the authors found that with regard to waste management options, research gaps identified by Brown et al. (2011a) were well addressed by Wakabayashi et al. (2017), Tabata et al. (2017), Portugal-Pereira and Lee (2016) and Brown and Milke (2016). However, the quantitative analyses regarding effectiveness and feasibility of waste treatments (e.g. incineration, landfill, recycling and waste to energy) were still absent, and it should be highlighted here that is due to two reasons.

Firstly, as an eco-friendly waste treatment, waste-to-energy has received growing attention but was abandoned by disaster managers because of the high initial costs (Yepsen. 2008). On the other hand, Portugal-Pereira and Lee (2016) contended that waste-to-energy approach was more cost-effective than other treatment approaches. Under this circumstance, it is important to further investigate these two completely opposite viewpoints.

Secondly, open burning is an effective way to dispose of disaster wastes within a limited time, but many people object to this process (Brown et al., 2011a). Additionally, overly aggressive recycling is counterproductive and can increase costs (Fetter and Rakes, 2012), although it is usually promoted by disaster managers and researchers. Consequently, the selection of waste treatment approaches is context specific, and many dimensions must be evaluated in the decision-making processes.

In summary, quantitative research is essential for helping to solve the problems that need to be 
more effectively addressed in improving the management of disaster-generated wastes.

\subsection{Environment}

According to Brown et al. (2011a), the standard of "peace-time" waste management followed the sequence of source reduction, recycling and waste incineration. However, such a standard is hard to use in the context of DWM, especially in time-pressure situations. Therefore, it is necessary to change the standard of "peace-time" waste management, to provide guidance for initial waste clean-up in the context of disasters.

\subsection{Economics}

The measurement of indirect economic effects is not well researched. To our knowledge, it is hard to distinguish indirect economic effects and social impacts. For example, job opportunities were identified as indirect economic effects according to the study of Brown et al. (2011a), which was supported by the research of Habib et al. (2019). Therefore, the measurement of indirect economic effects is discussed in subsection 5.6.

\subsection{Social considerations}

In recent years, qualitative analyses with respect to social considerations were effectively addressed, especially within the group of community interactions. However, investigations on psychological impacts of victims and of employees was limited. As Cao et al. (2018) and Cao et al. (2017) noted, the sustainability of the forward humanitarian supply chain was particularly impacted by the victim's perception of accessibility, equity and fulfillment. Similarly, management of disaster wastes was also linked to the perception about of accessibility, equity and fulfillment, which resulted from non-transparent priorities of waste management (Berktas et al., 2016). Additionally, the participant's direct access to humanitarian aid, and related social considerations (e.g. the potential risk of health and benefits from disaster waste cleanup) need to be considered to improve performance of waste management. (Aoki, 2018; Noh et al., 2015). Therefore, it is essential to work intensively with social considerations from the perspective of victims and employee and society as a whole, in the short and long-term.

As $\mathrm{Hu}$ and Sheu (2013) stated, that is it is essential to aggress social considerations in a quantitative way, which was also highlighted in DWM research of $\mathrm{Hu}$ et al. (2019). Idea is recommended to adopt the "prospect theory" to measure and response the psychological effects of victims (e.g. the perception of equity and fulfillment) as part of the process of recovering from the 
shocks of the disasters.

\subsection{Organizational aspects}

Regarding organizational aspects, 'coordination' was identified as a critical factor in achieving successful management of disaster wastes (Domingo and Luo, 2017; Hooper, 2019). However, there were no detailed directives of ways to establish the needed coordination. Based upon the extensive experiences in disaster operations management (Balcik et al., 2010; Li et al., 2019), organizational coordination was suggested as essential from three perspectives: a. stakeholder identification, $b$. coordinated network and c. coordination mechanism. Coordinated network is composed of several stakeholders, and it managed by coordination mechanism.

Based on the studies of Brown et al. (2011a), Karunasena et al. (2012), Kawamoto and Kim (2016) and Aoki (2018), government, the private sector and the communities are critical actors which influence the effectiveness of DWM. However, due to diverse norms, weak plans, lack of awareness regarding low level of trust (Hooper, 2019; Kawamoto and Kim, 2016; Aoki, 2018; Domingo and Luo, 2017), the effective coordinated network is hard to establish. Additionally, coordination mechanisms with regard to procurement, inventory, transportation and maintenance are often weak or totally absent. For example, coordinated decision-making processes between government and private sector are weak or non-existent but should be thoroughly investigated and integrated into the preparatory pre-contact phases (Brown et al., 2011a), to help to ensure answers to, whether to coordinate, when to coordinate and how to perform properly (Li et al., 2019).

\subsection{Legal frameworks}

Research gaps regarding legal frameworks can be summarized under two headings. Firstly, the lack of enforceable legislation was identified as a crucial capacity gap in developing countries, which resulted from little experience of DWM practice (Karunasena et al., 2012). Thus, how to establish enforceable regulations that a consistent with evolving legal frameworks (e.g. USEPA, 2008) to guide waste clean-up, are essential. Secondly, because regulations are mentioned generally but detailed components are not discussed in detailed cases and examples (Crowley and Flachsbart, 2018), consequently, the ambiguity of the relevant document results in managerial confusion. For example, the boundaries of adopting incineration plans is hard to be answered based upon existing legislation, therefore, this lack of clarity, negatively influences the effectiveness of waste clean-up planning and implementation of those plans (Brown et al., 2011a). Consequently, it is urgent that 
improvements are made in clarification of authority and operability of legal frameworks.

\subsection{Funding}

The conflict between fund-provider and fund-receiver was identified in subsection 4.9, which can be regarded as an integrated issue concerning disaster management and the financial problems. Generally, authors recognized that performance improvement is positively associated with sufficient funds, although such a viewpoint was opposed, due to cost of capital (Modigliani and Miller, 1958). Given the scarcity of funds, the needs of fund-receivers and the intentions of fund-providers should be well matched in the characteristics of funds, so that fund types (e.g. monetary funds, professional equipment and necessary relief), quantities of funds, qualities of funds (e.g. consistency of delivery

time between actual and expected, risk of capital), temporary and spatial use of funds are fully clarified, at the beginning of the clean-up processes.

For example, excessive unwanted donations (e.g. food and other supplies) sometimes cause extensive problem for responders and victims (Ekici et al., 2009), while other managers complained about lack of funds (Ardani et al., 2009) in the disposal of wastes. This example highlights the important roles of fund quantities in DWM. Consequently, it is important to design clear financial processes for raising and using the funds for the right places, with a high quality and in a certain time.

\section{Conclusions}

This paper provides an updated review of DWM. In detail, 82 papers were selected and systematically for this comprehensive literature review. The primary focus was upon pertaining to responses to disasters caused by diverse causes, with regard to: planning of responses in general, planning of quantification and management of the array of solid wastes according to diverse waste treatment options, in the context of environmental, economic, social considerations, organizational aspects, legal frameworks and funding.

The literature analyses revealed that there have been few dramatic improvements in the last 9 years in the field of DWM research, especially in the part of planning, organizational aspects, legislation and funding.

Although some of the technical aspects have been thoroughly investigated by researchers, to attract more interested researchers to address the research gaps, the following future research directions were outlined: a. establishing the DWM plan in terms of legal framework, organizational 
aspects and funding mechanism, b. analyzing case studies based on the specific disaster type, c. improving of the accuracy model with regard to estimate/predict disaster waste, $\mathrm{d}$. designing a quantitative analysis for analyzing the effectiveness and efficiency of waste treatment, e. analyzing the indirect economic effects and social considerations.

The limitations of this paper include:

a. the authors decide to limit our search to academic journals and conferences. However, policy statements, environmental programs and best-practice examples (e.g. Planning for Disaster Debris 1995; Public Assistance: Debris Management Guide 2007; Planning for Natural Disaster Debris 2008) were ignored, although these works provided useful and practical management insights for researchers (Brown et al., 2011a; Asari et al., 2013).

b. due to the keywords-based searching of publications, it was possible that publications matching the research question were not found, although the related contexts were discussed in the paper.

c. the selected papers were only published in English. Papers published in Japanese, Chinese, German, French and other languages were excluded, which may impact the results of the descriptive analysis and of the thematic analysis.

d. subjectivity may have influenced the process of the systematical literature review, such as the manual scrutiny of papers and the classification of papers.

\section{Acknowledgements}

This paper was supported by the National Natural Science Foundation of China with Grant No. 71672074, the Scientific Research Start-up Foundation for Introduction of Advanced Talents in Chongqing Technology and Business University with Grant No. 1955011, the Twelfth Five-Year Planning Project of Philosophy and Social Science of Guangdong Province with Grant No. GD15CGL07.

\section{References}

Abidi, H., de Leeuw, S., Klumpp, M., 2014. Humanitarian supply chain performance management: a systematic literature review.

Supply Chain Manag. 19(5-6), 592-608.

Allen, B.L., 2007. Environmental justice and expert knowledge in the wake of a disaster. Soc. Stud. Sci. 37(1), 103-110.

Altay, N., Green Ill, W.G., 2006. OR/MS research in disaster operations management. Eur. J. Oper. Res. 175(1), 475-493. 
Anaya-Arenas, A.M., Renaud, J., Ruiz, A., 2014. Relief distribution networks: a systematic review. Ann. Oper. Res. 223(1), 53-79.

Annarelli, A., Battistella, C., Nonino F., 2016. Product service system: A conceptual framework from a systematic review. J. Clean Prod. 139, 1011-1032.

Aoki, N., 2018. Who Would Be Willing to Accept Disaster Debris in Their Backyard? Investigating the Determinants of Public Attitudes in Post-Fukushima Japan. Risk Anal. 38(3), 535-547.

Ardani, K.B., Reith, C.C., Donlan, C.J., et al., 2009. Harnessing Catastrophe to Promote Resource Recovery and Eco-industrial Development. J. Ind. Ecol. 13(4), 579-591.

Asari, M., Sakai, S.I., Yoshioka, T., et al., 2013. Strategy for separation and treatment of disaster waste: a manual for earthquake and tsunami disaster waste management in Japan. J. Mater. Cycles Waste Manag. 15(3), 290-299.

Askarizadeh, L., Karbassi, A.R., Ghalibaf, M.B., et al., 2016. Management of post-earthquake construction debris in Tehran Metropolitan. Int. J. Environ. Sci. Te. 13(2), 639-648.

Askarizadeh, L., Karbassi, A.R., Ghalibaf, M.B., et al., 2017. Debris management after earthquake incidence in ancient City of Ray. Global Journal of Environmental Science and Management. 3(4), 447-456.

Baek, S.C., Kim, Y.C., Choi, J.H., et al., 2016. Determination of the essential activity elements of an asbestos management system in the event of a disaster and their prioritization. J. Clean Prod. 137, 414-426.

Balcik, B., Beamon, B.M., Krejci, C.C., et al., 2010. Coordination in humanitarian relief chains: practices, challenges and opportunities. Int. J. Prod. Econ. 126(1), 22-34.

Beraud, H., Barroca, B., Hubert, G., 2012. Functional analysis, a resilience improvement tool applied to a waste management system application to the "household waste management chain". Nat. Hazards Earth Syst. Sci. 12(12), 3671-3682.

Berktaş, N., Kara, B.Y., Karaşan, O.E., 2016. Solution methodologies for debris removal in disaster response. EURO Journal on Computational Optimization. 4(3-4), 403-445.

Boehm, M., Thomas, O., 2013. Looking beyond the rim of one's teacup: a multidisciplinary literature review of Product-Service Systems in Information Systems, Business Management, and Engineering \& Design. J. Clean Prod. 51, 245-260.

Boonmee, C., Arimura, M., Asada, T., 2018. Location and allocation optimization for integrated decisions on postdisaster waste supply chain management: On-site and off-site separation for recyclable materials. Int. J. Disaster Risk Reduct. 31, 902-917.

Brown, C., Milke, M., 2016. Recycling disaster waste: Feasibility, method and effectiveness. Resour. Conserv. Recycl. 106, 21-32.

Brown, C., Milke, M., Seville, E., 2011a. Disaster waste management: A review article. Waste Manage. 31(6), 1085-1098.

Brown. C., Milke, M., Seville, E., 2011b. Disaster waste management following the 2009 Victorian bushfires. Australian Journal of Emergency Management. 26(2), 497-509.

Calabrese, A., Castaldi, C., Forte, G., et al., 2018. Sustainability-oriented service innovation: An emerging research field. J. Clean Prod. 193, 533-548.

Caniato, M., Tudor, T.L., Vaccari, M., 2016. Assessment of health-care waste management in a humanitarian crisis: A case study of the Gaza Strip. Waste Manage. 58, 386-396.

Cao, C.J., Li, C.D., Yang, Q., et al., 2017. Multi-Objective Optimization Model of Emergency Organization Allocation for Sustainable Disaster Supply Chain. Sustainability. 9(11), 2103.

Cao, C.J., Li, C.D., Yang, Q., et al., 2018. A novel multi-objective programming model of relief distribution for sustainable disaster 
supply chain in large-scale natural disasters. J. Clean Prod. 174, 1422-1435.

Çelik, M., Ergun, Ö., Keskinocak, P., 2015. The Post-Disaster Debris Clearance Problem Under Incomplete Information. Oper. Res. $63(1), 65-85$.

Cheng, C., Thompson, R.G., 2016. Application of boolean logic and GIS for determining suitable locations for Temporary Disaster Waste Management Sites. Int. J. Disaster Risk Reduct. 20, 78-92.

Cheng, C., Zhang, L.H., Thompson, R.G., 2018a. Reliability analysis for disaster waste management systems. Waste Manage. 78, $31-42$.

Cheng, C., Zhang, L.H., Thompson, R.G., 2018b. Disaster waste clean-up system performance subject to time-dependent disaster waste accumulation. Nat. Hazards. 91(2), 717-734.

Cheng, C., Zhang, L.H., Thompson, R.G., 2019. Reliability analysis of road networks in disaster waste management. Waste Manage. DOI: 10.1016/j.wasman.2018.11.027

Cook, D.J., Mulrow, C.D., Haynes, R.B., 1997. Systematic Reviews: Synthesis of Best Evidence for Clinical Decisions. Ann. Intern. Med. 126(5), 376-380.

Crowley, J., 2017. A measurement of the effectiveness and efficiency of pre-disaster debris management plans. Waste Manage. 62, $262-273$

Crowley, J., Flachsbart, J., 2018. Local debris management planning and FEMA policies on disaster recovery in the United States. Int.

J. Disaster Risk Reduct. 27, 373-379.

Denot, A., 2016. Prevention and management of waste resulting from natural disasters. Waste Manage. 58, 1-2.

Domingo, N., Luo, H., 2017. Canterbury earthquake construction and demolition waste management: issues and improvement suggestions. Int. J. Disaster Risk Reduct. 22, 130-138.

Dubey, B., Solo-Gabriele, H.M., Townsendt, T.G., 2007. Quantities of arsenic-treated wood in demolition debris generated by Hurricane Katrina. Environ. Sci. Technol. 41(5), 1533-1536.

Dubey, R., Altay, N., 2018. Drivers of coordination in humanitarian relief supply chains. In The Palgrave Handbook of Humanitarian Logistics and Supply Chain Management. Palgrave Macmillan, London, 297-637.

Ekici, S., Mcentire, D.A., Afedzie, R., 2009. Transforming debris management: considering new essentials. Disaster Prev. Manag. 18(5), 511-522.

Faleschini, F., Zanini, M.A., Hofer, L., et al., 2017. Sustainable management of demolition waste in post-quake recovery processes: The Italian experience. Int. J. Disaster Risk Reduct. 24, 172-182.

Fetter, G., Rakes, T.R., 2011. A self-balancing CUSUM approach for the efficient allocation of resources during post-disaster debris disposal operations. Oper. Manag. Res. 4(1-2), 51-60.

Fetter, G., Rakes, T.R., 2012. Incorporating recycling into post-disaster debris disposal. Socio-Econ. Plan. Sci. 46(1), 14-22.

Fetter, G., Rakes, T.R., 2013. An equity approach to contractor assignment in post-disaster debris disposal operations. International Journal of Emergency Management. 9(2), 170-186.

Francesco, G., Alessia, A., Susanna, B., et al., 2018. Disaster waste management in Italy: Analysis of recent case studies. Waste Manage. 71, 542-555.

Galindo, G., Batta, R., 2013. Review of recent developments in OR/MS research in disaster operations management. Eur. J. Oper. Res. 
230(2), 201-211.

García-Torres, S., Kahhat, R., Santa-Cruz, S., 2018. Methodology to characterize and quantify debris generation in residential buildings after seismic events. Resour. Conserv. Recycl. 117, 151-159.

Geraldi, J., Maylor, H., Williams, T., 2011. Now, let's make it really complex (complicated) A systematic review of the complexities of projects. Int. J. Oper. Prod. Manage. 31(9-10), 966-990.

Grzeda, S., Mazzuchi, T.A., Sarkani, S., 2014. Temporary disaster debris management site identification using binomial cluster analysis and GIS. Disasters. 38(2), 398-419

Gupta, S., Starr, M.K., Farahani, R.Z., et al., 2016. Disaster Management from a POM Perspective: Mapping a New Domain. Prod. Oper. Manag. 25(10), 1611-1637.

Habib, M.S., Sarkar, B., Tayyab, Muhammad., et al., 2019. Large-scale disaster waste management under uncertain environment. J. Clean Prod. 212:200-222.

Habib, M.S., Sarkar, B., 2017. An Integrated Location-Allocation Model for Temporary Disaster Debris Management under an Uncertain Environment. Sustainability. 9(5), 10.3390/su9050716.

Hooper, M., 2019. When Diverse Norms Meet Weak Plans: The Organizational Dynamics of Urban Rubble Clearance in Post-Earthquake Haiti. International Journal of Urban and Regional Research. 43 (2), 292-312.

Hu, Z.H., Sheu, J.B., 2013. Post-disaster debris reverse logistics management under psychological cost minimization. Transp. Res. Pt. B-Methodol. 55, 118-141.

Hu, Z.H., Sheu, J.B., Wei, C., et al., 2019. Post-storm debris removal considering traffic and psychological impacts. DOI: $10.1080 / 23249935.2019 .1567618$.

Jiang, S.S., Friedland, C.J., 2016. Automatic urban debris zone extraction from post-hurricane very high-resolution satellite and aerial imagery. Geomat. Nat. Hazards Risk. 7(3), 933-952.

Karunasena, G., Amaratunga, D., 2015. Capacity gaps in post disaster construction \& demolition waste management. Eng. Constr. Archit. Manag. 22(4), 446-466.

Karunasena, G., Amaratunga, D., Haigh, D., et al., 2009. Post disaster waste management strategies in developing countries: Case of Sri Lanka. Int. J. Strateg. Prop. Manag. 13(2), 171-190.

Karunasena, G., Amaratunga, D., Haigh, R., 2012. Post-disaster construction \& demolition debris management: a Sri Lanka case study. J. Civ. Eng. Manag. 18(4), 457-468

Karunasena, G., Amaratunga. D., 2016. Capacity building for post disaster construction and demolition waste management: a case of Sri Lanka. Disaster Prev. Manag.25(2), 137-153.

Kawamoto, K., Kim, K., 2016. Social capital and efficiency of earthquake waste management in Japan. Int. J. Disaster Risk Reduct. $18,256-266$

Kawamoto, K., Kim, K., 2019. Efficiencies of bonding, bridging and linking social capital: Cleaning up after disasters in Japan. Int. J. Disaster Risk Reduct. 33, 64-73.

Kim, J., Deshmukh, A., Hastak, M.A., 2018. A framework for assessing the resilience of a disaster debris management system. Int. J. Disaster Risk Reduct. 28, 674-687.

Kim, T., Kim, T., 2017. Smart and resilient urban disaster debris cleanup using network analysis. Spatial Information Research. 25(2), 
239-248.

Kim, Y.C., Hong, W.H., 2017. Optimal management program for asbestos containing building materials to be available in the event of a disaster. Waste Manage. 64, 272-285.

Koyama, C.N., Gokon, H., Jimbo, M., et al., 2016. Disaster debris estimation using high-resolution polarimetric stereo-SAR. ISPRS-J. Photogramm. Remote Sens. 120, 84-98.

Leader, A., Gaustad, G., Tomaszewski, B., 2018. The Consequences of Electronic Waste Post-Disaster: A Case Study of Flooding in Bonn, Germany. Sustainability. 10(11), DOI: 10.3390/su10114193.

Leseure, M.J., Bauer, J., Birdi, K., et al., 2004. Adoption of promising practices: a systematic review of the evidence. Int. J. Manag. Rev. 5-6(3-4), 169-190.

Lesperance, A.M., Stein, S., Upton, J.F., et al., 2011. Challenges in Disposing Anthrax Waste. Biosecurity and Bioterrorism -Biodefense Strategy Practice and Science. 9(3), 310-314.

Li, C.D., Zhang, F.S., Cao, C.J., et al., 2019. Organizational coordination in sustainable humanitarian supply chain: an evolutionary game approach. J. Clean Prod. 219, 291-303.

Lorca, Á., Cedil, M., Ergun. Ö., et al., 2017. An Optimization-Based Decision-Support Tool for Post-Disaster Debris Operations. Prod. Oper. Manag. 26(6), 1076-1091.

Maryono., Nakayama, H., Shimaoka, T., 2015. Identification of factors affecting stakeholders' intentions to promote preparedness in disaster waste management: A structural equation modeling approach. Memoirs of the Faculty of Engineering. 74(3), 79-98.

Memon, M.A., 2015. Disaster waste recovery and utilization in developing countries - Learning from earthquakes in Nepal. In: The 15th Asian Regional Conference on Soil Mechanics and Geotechnical Engineering. Japan, 143-147.

Milke, M., 2011. Disaster waste management research needs. Waste Manage. 31(1), 1.

Misra, D., Das, G., Chakrabortty, T., et al., 2018. An IoT-based waste management system monitored by cloud. J. Mater. Cycles Waste Manag. 20(3), 1574-1582.

Modigliani, F., Miller, H.M., 1958. The Cost of Capital, Corporation Finance and the Theory of Investment. Am. Econ. Rev. 48(3), 261-297.

Noh, S.R., Cheong, H.K., Ha, M., et al., 2015. Oxidative stress biomarkers in long-term participants in clean-up work after the Hebei Spirit oil spill. Sci. Total Environ. 515, 207-214.

Nurmala, N., Leeuw, S., Dullaert, W., 2017. Humanitarian-business partnerships in managing humanitarian logistics. Supply Chain Manag. 22(1), 82-94.

Onan, K., Ulengin, F., Sennaroglu, B., 2015. An evolutionary multi-objective optimization approach to disaster waste management: A case study of Istanbul, Turkey. Expert Syst. Appl. 45(22), 8850-8857.

Otsuka, Y., Katsumi, T., 2015. Analysis of the integrated data on disaster debris treatment in Yamada town, Iwate prefecture. In: The 15th Asian Regional Conference on Soil Mechanics and Geotechnical Engineering. Japan, 154-157.

Ozdamar, L., Aksu, D.T., Ergunes, B., 2014. Coordinating debris cleanup operations in post disaster road networks. Socio-Econ. Plan. Sci. 48(4), 249-262

Periathamby, A., Hamid, F.S., Sakai, S., 2012. Disaster waste management challenges. Waste Manage. Res. 30(2), 113-114.

Pham, T.T.H., Apparicio, P., Gomez, C., et al., 2014. Towards a rapid automatic detection of building damage using remote sensing 
for disaster management: The 2010 Haiti earthquake. Disaster Prev. Manag. 23(1), 53-66.

Phonphoton, N., Pharino, C., 2019. A system dynamics modeling to evaluate flooding impacts on municipal solid waste management services. Waste Manage. 87,525-536.

Portugal-Pereira, J., Lee, L., 2016. Economic and environmental benefits of waste-to-energy technologies for debris recovery in disaster-hit Northeast Japan. J. Clean Prod. 112, 4419-4429.

Poudel, R., Hirai, Y., Asari, M., et al., 2018. Establishment of unit generation rates of building debris in Kathmandu Valley, Nepal, after the Gorkha earthquake. J. Mater. Cycles Waste Manag. 20(3), 1663-1675.

Pramudita, A., Taniguchi, E., 2014. Model of debris collection operation after disasters and its application in urban area. International Journal of Urban Sciences. 18(2), 218-243.

Prasetya, G., Black, K., Lange, W.D., et al., 2012. Debris dispersal modeling for the great Sumatra Tsunamis on Banda Aceh and surrounding waters. Nat. Hazards. 60(3), 1167-1188.

Raila, E.M., Anderson, D.O., 2017. Healthcare waste management during disasters and its effects on climate change: Lessons from 2010 earthquake and cholera tragedies in Haiti. Waste Manage. Res. 35(3), 236-245.

Regattieri, A., Gamberi, M., Bortolini, M., et al., 2018. Innovative Solutions for Reusing Packaging Waste Materials in Humanitarian Logistics. Sustainability. 10(5), DOI:10.3390/su10051587.

Regattieri, A., Piana, F., Bortolini, M., et al., 2016. Innovative portable solar cooker using the packaging waste of humanitarian supplies. Renew. Sust. Energ. Rev. 57, 319-326.

Reim, W., Parida, V., Ortqvist, D., 2015. Product-Service Systems (PSS) business models and tactics - a systematic literature review.

J. Clean Prod. 97, 61-75.

Saat, N.Z.M., Nor Malia, W.A., Muhammad Ikram, A.W., et al., 2016. Perception of Flood Waste Management Among Stakeholders in Kelantan. J. Environ. Sci. Technol. 9(4), 317-322.

Saffarzadeh, A., Shimaoka, T., Nakayama, H., et al., 2017. Tasks and problems involved in the handling of disaster waste upon April 2016 Kumamoto Earthquake, Japan. Nat. Hazards. 89(3), 1273-1290.

Sahin, H., Kara, B.Y., Karasan, O.E., 2016. Debris removal during disaster response: A case for Turkey. Socio-Econ. Plan. Sci. 53, $49-59$.

Sakai, S., Poudel, R., Asari, M., et al., 2019. Disaster waste management after the 2016 Kumamoto Earthquake: A mini-review of earthquake waste management and the Kumamoto experience. Waste Manage. Res. 37(3), 247-260.

Sanders, D.R., Manfredo, M.R., 2006. Forecasting Basis Levels in the Soybean Complex: A Comparison of Time Series Methods. Journal of Agricultural and Applied Economics. 38(3), 513-523.

Sasao, T., 2016. Cost and efficiency of disaster waste disposal: A case study of the Great East Japan Earthquake. Waste Manage. 58, 3-13.

Shibata, T., Sologabriele, H., Hata, T., 2012. Disaster Waste Characteristics and Radiation Distribution as a Result of the Great East Japan Earthquake. Environ. Sci. Technol. 46(7), 3618-3624.

Szantoi, Z., Malone, S., Escobedo, F., et al., 2012. A tool for rapid post-hurricane urban tree debris estimates using high resolution aerial imagery. Int. J. Appl. Earth Obs. Geoinf. 18, 548-566.

Tabata, T., Morita, H., Onishi, A., 2018. What is the quantity of consumer goods stocked in a Japanese household? Estimating 
potential disaster waste generation during floods. Resour. Conserv. Recycl. 133, 86-98.

Tabata, T., Wakabayashi, Y., Tsai, P., et al., 2017. Environmental and economic evaluation of pre-disaster plans for disaster waste management: Case study of Minami-Ise, Japan. Waste Manage. 61, 386-396.

Tabata, T., Zhang, O., Yamanaka, Y., et al., 2016. Estimating potential disaster waste generation for pre-disaster waste management. Clean Technol. Environ. Policy. 18(6), 1735-1744.

Taebi, B., van de Poel, I., 2015. The socio-technical challenges of nuclear power production and waste management in the post-Fukushima era: editors' overview. J. Risk Res. 18(3), 267-272.

Takeda, T., Mori, Y., Kubota, N., et al., 2015. A route planning for disaster waste disposal based on robot technology. In: IEEE Symposium on Robotic Intelligence in Informationally Structured Space. Orlando, Florida, 74-79.

The Central People's Government of the People's Republic of China., 2008. Guidelines for Disaster Waste Management. Available at: http://www.gov.cn/gzdt/2008-05/24/content_991314.htm.

Thompson, B.K., Escobedo, F.J., Staudhammer, C.L., et al., 2011. Modeling hurricane-caused urban forest debris in Houston, Texas. Landsc. Urban Plan. 101(3), 286-297.

Tranfield, D., Denyer, D., Smart, P., 2003. Towards a methodology for developing evidence-informed management knowledge by means of systematic review. Brit. J. Manage. 14(3), 207-222.

Trivedi, A., Singh, A., Chauhan, A., 2015. Analysis of key factors for waste management in humanitarian response: An interpretive structural modelling approach. Int. J. Disaster Risk Reduct. 14(4), 527-535.

United Nations., 2018. Human Development Reports. Available at: http://hdr.undp.org/en/content/developing-regions.

United States Environmental Protection Agency (USEPA),, 2008. Planning for natural disaster debris. Available at: https://www.epa.gov/sites/production/files/2015-08/documents/pndd.pdf.

United States Environmental Protection Agency, (USEPA),, 1995. Planning for disaster debris. Available at: https://permanent.access.gpo.gov/lps29601/dstr-pdf.pdf.

Wakabayashi, Y., Peii, T., Tabata, T., et al., 2017. Life cycle assessment and life cycle costs for pre-disaster waste management systems. Waste Manage. 68, 688-700.

Wang, T.Q., Kim, J., Whelton, A.J., 2019. Management of plastic bottle and filter waste during the large-scale Flint Michigan lead contaminated drinking water incident. Resour. Conserv. Recycl. 140:115-124.

Wang, Z.J., Hu, H., Guo, M.Y., et al., 2019. Optimization of Temporary Debris Management Site Selection and Site Service Regions for Enhancing Post disaster Debris Removal Operations. Comput.-Aided Civil Infrastruct. Eng. 34(3), 230-247.

Xiao, J.Z., Xie, H., Zhang, C., 2012. Investigation on building waste and reclaim in Wenchuan earthquake disaster area. Resour. Conserv. Recycl. 61, 109-117.

Yepsen R., 2008. Generating biomass fuel from disaster debris. Biocycle. 49, 51.

Yoo, H.T., Lee, H., Chi, S., et al., 2017. A Preliminary Study on Disaster Waste Detection and Volume Estimation Based on 3D Spatial Information. In: ASCE International Workshop on Computing in Civil Engineering. Washington, the United States, 428-435.

Yusof, N.S., Zawawi, E.M.A., Ismail, Z., 2016. Disaster Waste Management in Malaysia: Significant Issues, Policies \& Strategies. In: 4th International Building Control Conference. Kuala Lumpur, Malaysia, 1-7. 
Zawawi, E.M.A., Yusof, N.S., Ismail, Z., 2018. Adoption of post-disaster waste management plan into disaster management guidelines for Malaysia. J. Mater. Cycles Waste Manag. 20(1), 223-236.

Zawawi, E.M.A., Yusof, N.S., Kamaruzzaman, S.N., et al., 2015. Important criteria for managing disaster waste in Malaysia. Jurnal Teknologi. 75(9), 89-93.

Zhang, H., Duan, H., Zuo, J., et al., 2017. Characterization of post-disaster environmental management for Hazardous Materials Incidents: Lessons learnt from the Tianjin warehouse explosion, China. J. Environ. Manage. 199, 21-30.

Zhang, L., Wu, L.H., Tian, F., et al., 2016. Retrospection-Simulation-Revision: Approach to the Analysis of the Composition and Characteristics of Medical Waste at a Disaster Relief Site. PLoS One. DOI: 10.1371/journal.pone.0159261. 


\section{Highlights}

- A systematic review is done towards recent advances in disaster waste management.

- There are no dramatic development in the field of disaster waste management.

- Recent studies also focus on technical aspects.

- Planning, legislation, organizations and funding are still not well addressed.

- Future research directions are proposed. 